\title{
Structural Developments in Tall Buildings: Current Trends and Future Prospects
}

\author{
Mir M. Ali ${ }^{\dagger}$ and Kyoung Sun Moon \\ Structures Division, School of Architecture, University of Illinois at Urbana-Champaign, Champaign, IL 61820, USA \\ ${ }^{\dagger}$ Corresponding Author: Tel: + 1217333 1330; Fax: +1 217244 2900; E-mail: mirali1@uiuc.edu
}

Received 8 May; accepted 13 June 2007

\begin{abstract}
Tall building developments have been rapidly increasing worldwide. This paper reviews the evolution of tall building's structural systems and the technological driving force behind tall building developments. For the primary structural systems, a new classification - interior structures and exterior structures - is presented. While most representative structural systems for tall buildings are discussed, the emphasis in this review paper is on current trends such as outrigger systems and diagrid structures. Auxiliary damping systems controlling building motion are also discussed. Further, contemporary "out-of-the-box" architectural design trends, such as aerodynamic and twisted forms, which directly or indirectly affect the structural performance of tall buildings, are reviewed. Finally, the future of structural developments in tall buildings is envisioned briefly.
\end{abstract}

Keywords: Aerodynamics, Building forms, Damping systems, Diagrid structures, Exterior structures, Interior structures, Outrigger systems, Structural performance, Structural systems, Tall buildings

\section{Introduction}

Tall buildings emerged in the late nineteenth century in the United States of America. They constituted a so-called "American Building Type," meaning that most important tall buildings were built in the U.S.A. Today, however, they are a worldwide architectural phenomenon. Many tall buildings are built worldwide, especially in Asian countries, such as China, Korea, Japan, and Malaysia. Based on data published in the 1980 s, about $49 \%$ of the world's tall buildings were located in North America (Table 1-1). The distribution of tall buildings has changed radically with Asia now having the largest share with 32\%, and North America's at 24\% (Table 1-2). This data demonstrates the rapid growth of tall building construction in Asian during this period while North American construction has slowed. In fact, eight of the top ten tall buildings are now in Asia and only two, the Sears Tower and the Empire State Building, are in North America.

Traditionally the function of tall buildings has been as commercial office buildings. Other usages, such as residential, mixed-use, and hotel tower developments have since rapidly increased as Figure 1 shows. There has been some skepticism regarding construction of tall buildings since September 11,2001, however, they will continue to be built due to their significant economic benefits in dense urban land use.

Tall building development involves various complex factors such as economics, aesthetics, technology, municipal regulations, and politics. Among these, economics has been the primary governing factor. This new building type itself would not have been possible, however, without supporting technologies. A structural revolution - the steel skeletal structure - as well as consequent glass curtain wall systems, which occurred in Chicago, has led to the present state-of-the-art skyscraper. While this review paper encompasses the development spectrum of tall building's structural systems, there is emphasis on current trends. Speculations of future prospects of structural developments in tall buildings are based on this review.

\section{Developments of Structural Systems}

Structural development of tall buildings has been a continuously evolving process. There is a distinct structural history of tall buildings similar to the history of their architectural styles in terms of skyscraper ages (Ali \& Armstrong, 1995; Huxtable, 1984). These stages range from the rigid frame, tube, core-outrigger to diagrid

Table 1-1: Tall Buildings in Regions (ca. 1982).

\begin{tabular}{|l|c|c|c|}
\hline REGION & $\begin{array}{c}\text { COUNTRIES } \\
\text { (No.) }\end{array}$ & $\begin{array}{c}\text { PERCENT } \\
(\mathbf{\%})\end{array}$ & $\begin{array}{c}\text { BUILDINGS } \\
\text { (No.) }\end{array}$ \\
\hline North America & 4 & 48.9 & 1,701 \\
\hline Europe & 35 & 21.3 & 742 \\
\hline Asia & 35 & 20.2 & 702 \\
\hline South America & 13 & 5.2 & 181 \\
\hline Australia & 2 & 1.6 & 54 \\
\hline Middle East & 15 & 1.5 & 51 \\
\hline Africa & 41 & 1.3 & 47 \\
\hline Mid-America & 20 & 0.1 & 4 \\
\hline TOTAL & $\mathbf{1 6 5}$ & & $\mathbf{3 , 4 8 2}$ \\
\hline
\end{tabular}


systems. A brief account of past developments in tall buildings is presented below.

\section{Brief History}

In the late nineteenth century, early tall building developments were based on economic equations - increasing rentable area by stacking office spaces vertically and maximizing the rents of these offices by introducing as much natural light as possible. In order to serve this economic driver, new technologies were pursued that improved upon the conventional load-bearing masonry walls that had relatively small punched openings. The result was the iron/steel frame structure which minimized the depth and width of the structural members at building perimeters.

Consequently, the larger openings were filled with transparent glasses, while the iron/steel structures were clad with other solid materials such as brick or terra cotta. Different from traditional load-bearing masonry walls, these claddings did not carry any loads from buildings except their own weights and the lateral wind pressure. A new cladding concept - curtain walls - was developed with the emergence of the new structural systems.

The symbolic power of skyscrapers being recognized, a notable phenomenon occurred from the turn of the century. A skyscraper height race began, starting from the Park Row Building in New York, which had already reached 30 stories in 1899. This height race culminated with the completion of the 102-story tall Empire State Building in 1931. Even though the heights of skyscrapers were significantly increased during this period, contrary to intuition, there had not been much conspicuous technological evolution. In terms of structural systems, most tall buildings in the early twentieth century employed steel rigid frames with wind bracing. Among them are the renowned Woolworth Building of 1913, Chrysler Building of 1930 and Empire State Building of 1931 all in New York (Ali, 2005). Their enormous heights at that time were accomplished not through notable technological evolution, but through excessive use of structural materials. Due to the absence of advanced structural analysis techniques, they were quite over-designed.

In terms of architectural expression of tall buildings at this time period, as can be observed from many eclectic style tall buildings, architects returned to the traditional architecture for representational quality, after a short pursuit of a new style for a

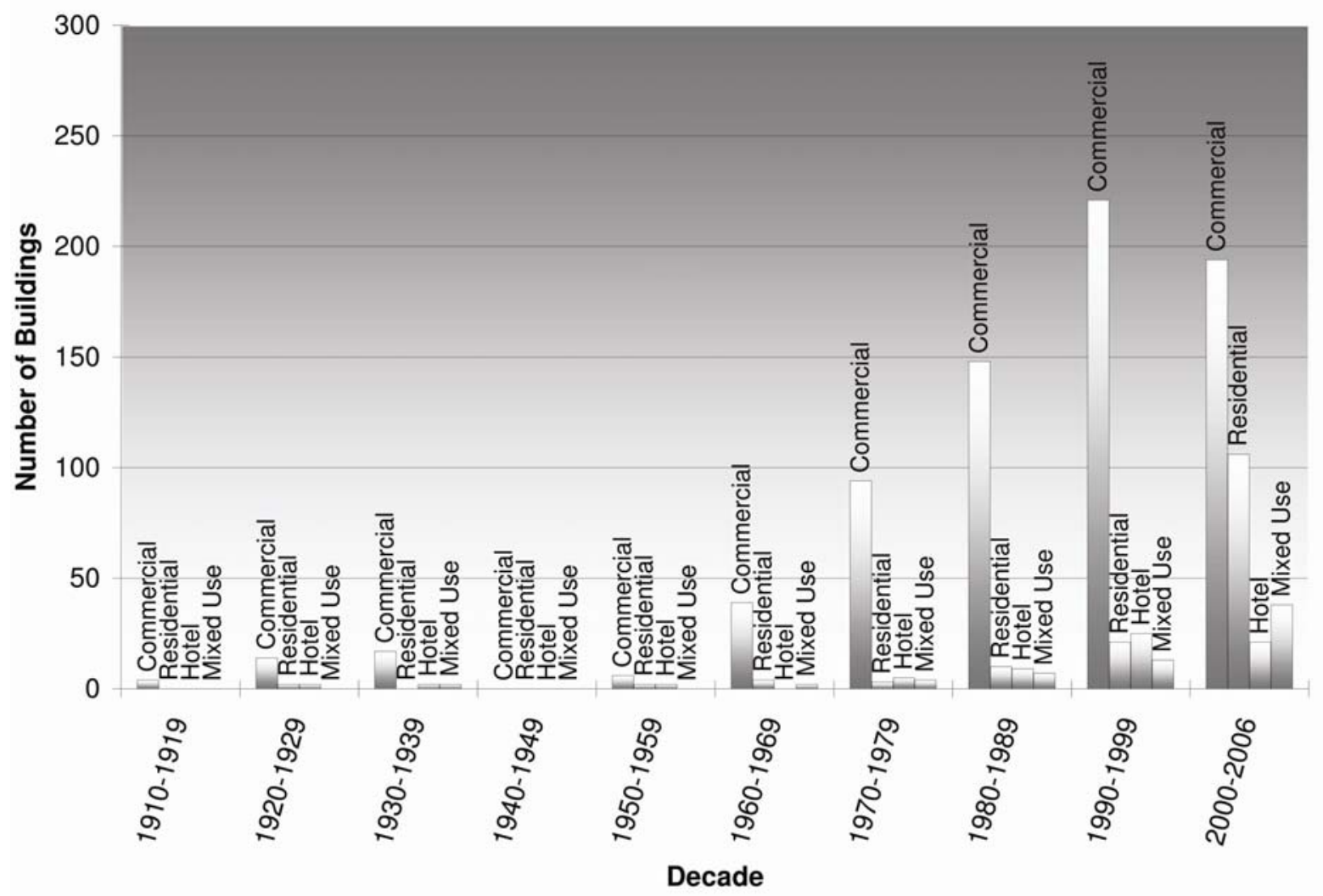

Figure 1: Building type distribution. 
new building type based on new technologies mostly by Chicago architects in the late nineteenth century. However, the rebirth of the early Chicago spirit and the application of European modern movements to tall buildings were only a matter of time.

The mid-twentieth century, after the war, was the era of mass production based on the International Style defined already before the war, and the technology developed earlier. The major driving force of tall building developments was economy. Even the onceprevalent height race did not occur after World War II until the construction of the World Trade Center in New York and the Sears Tower in Chicago, completed in 1973 and 1974 , respectively.

Structural systems for tall buildings have undergone dramatic changes since the demise of the conventional rigid frames in the 1960s as the predominant type of structural system for steel or concrete tall buildings. With the emergence of the tubular forms still conforming to the International Style, such changes in the structural form and organization of tall buildings were necessitated by the emerging architectural trends in design in conjunction with the economic demands and technological developments in the realms of rational structural analysis and design made possible by the advent of high-speed digital computers. Beginning in the 1980s, once-prevalent Miesian tall buildings were then largely replaced by the façade characteristics of postmodern, historical, diagrid and deconstructivist expressions. This was not undesirable because the new generation of tall buildings broke the monotony of the exterior tower form and gave rise to novel high-rise expressions. Innovative structural systems involving tubes, megaframes, core-and-outrigger systems, artificially damped structures, and mixed steel-concrete systems are some of the new developments since the 1960s.

\section{Premium for Height}

The primary structural skeleton of a tall building can be visualized as a vertical cantilever beam with its base fixed in the ground. The structure has to carry the vertical gravity loads and the lateral wind and earthquake loads. Gravity loads are caused by dead and live loads. Lateral loads tend to snap the building or topple it. The building must therefore have adequate shear and bending resistance and must not lose its vertical load-carrying capability.

Fazlur Khan realized for the first time that as buildings became taller, there is a "premium for height" due to lateral loads and the demand on the structural system dramatically increased, and as a result, the total structural material consumption increases drastically (Ali, 2001). If there would be no lateral forces on the building such as wind or earthquake, any high-rise building could be designed just for gravity loads. The floor framing system usually carries almost the same gravity loads at each floor, although the girders along the column lines need to be progressively heavier towards the base of the building to carry increasing lateral forces and to augment the building's stiffness. The column sizes increase progressively towards the base of the building due to the accumulated increase in the gravity loads transmitted from the floors above. Further to this, the columns need to be even heavier towards the base to resist lateral loads. The net result is that as the building becomes taller and the building's sway due to lateral forces becomes critical, there is a greater demand on the girders and columns that make up the rigid-frame system to carry lateral forces. The concept of premium for height is illustrated in Figure 2.

If we assume the same bay sizes, the material quantities required for floor framing is almost the same regardless of the number of stories. The material needed for floor framing depends upon the span of the framing elements, that is, column-to-column distance and not on the building height. The quantity of materials required for resisting lateral loads, on the other hand, is even more increased and would begin to exceed other structural costs if a rigid-frame system is used for very tall structures. This calls for a structural system that goes well beyond the simple rigid frame concept. Based on his investigations Khan argued that as the height increases beyond 10 stories, the lateral drift starts controlling the design, the stiffness rather than strength becomes the dominant factor, and the premium for height increases rapidly with the number of stories. Following this line of reasoning, Khan recognized that a hierarchy of structural systems could be categorized with respect to relative effectiveness in resisting lateral loads for buildings beyond the 20- to 30-story range (Khan, 1969).

\section{Classification of Tall Building Structural Systems}

In 1969 Fazlur Khan classified structural systems for tall buildings relating to their heights with considerations for efficiency in the form of "Heights for Structural Systems" diagrams (Khan, 1969). This marked the beginning of a new era of skyscraper revolution in terms of multiple structural systems. Later, he upgraded these diagrams by way of modifications (Khan, 1972, 1973). He developed these schemes for both steel and concrete as can be seen from Figure 3 (Ali, 2001; Ali \& Armstrong, 1995; Schueller, 1986). Khan argued that the rigid frame that had dominated tall building design and construction so long was not the only system fitting for tall buildings. Because of a better understanding of the mechanics 

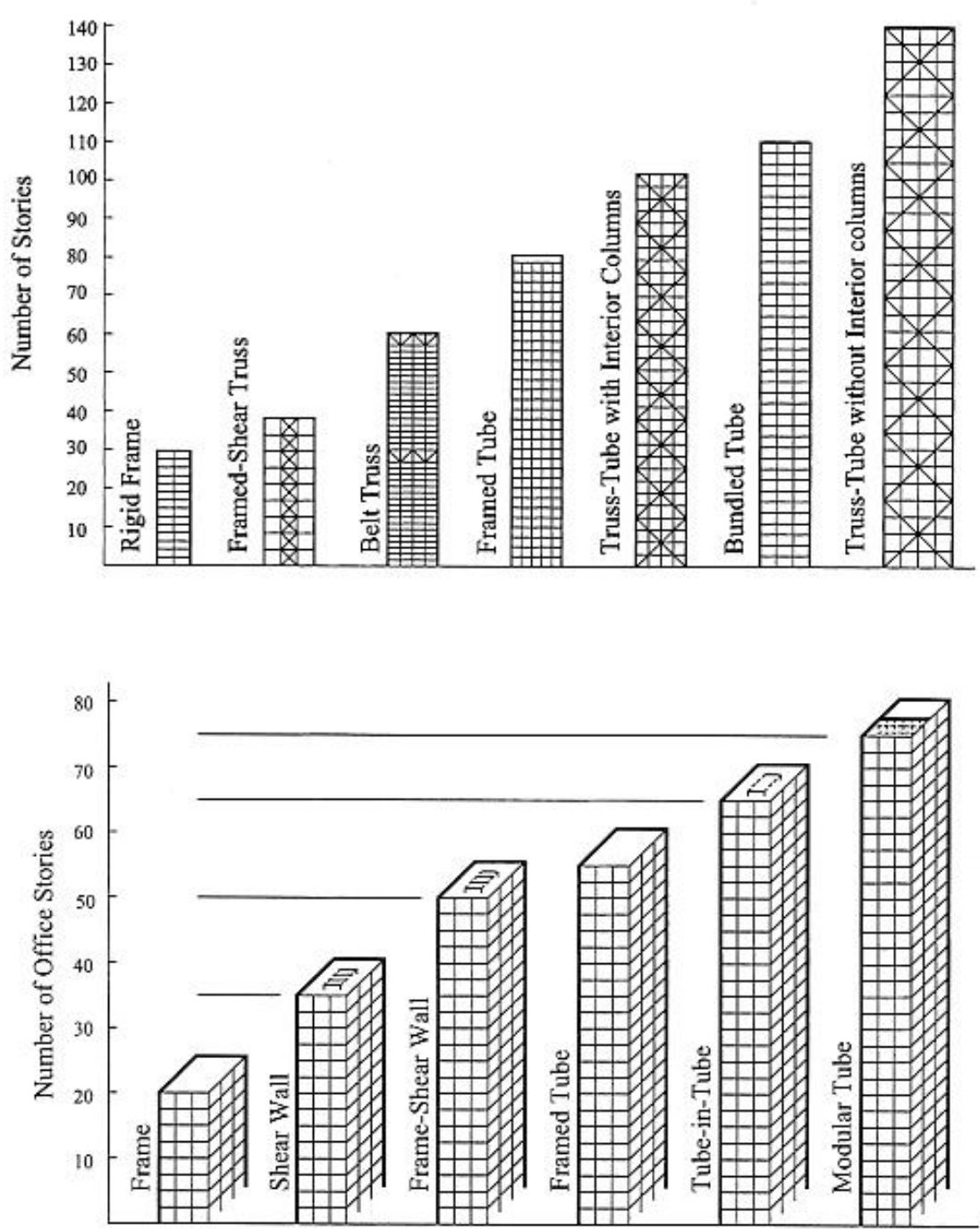

Figure 3: Classification of tall building structural systems by Fazlur Khan (above: steel; below: concrete).

of material and member behavior, he reasoned that the structure could be treated in a holistic manner, that is, the building could be analyzed in three dimensions, supported by computer simulations, rather than as a series of planar systems in each principal direction. Feasible structural systems, according to him, are rigid frames, shear walls, interactive frame-shear wall combinations, belt trusses, and the various other tubular systems.

This paper presents a new classification by the authors, which encompasses most representative tall building structural systems today. The classification is performed for both primary structures and subsequently auxiliary damping systems. Recognizing the importance of the premium for heights for tall buildings, the classification of structural systems is based on lateral load-resisting capabilities.

Structural systems of tall buildings can be divided into two broad categories: interior structures and exterior structures. This classification is based on the distribution of the components of the primary lateral load-resisting system over the building. A system is categorized as an interior structure when the major part of the lateral load resisting system is located within the interior of the building. Likewise, if the major part of the lateral load-resisting system is located at the building perimeter, a system is categorized as an exterior structure. It should be noted, however, that any interior structure is likely to have some minor components of the lateral load-resisting system at the building perimeter, and any exterior structure may have some minor components within the interior of the building.

Tables 2-1 and 2-2 summarize the details of the systems in each category. In addition, Figure 4-1 and 4-2 show the concept of each system diagrammatically. This classification of structural systems is presented more as a guideline and should be treated as such. It is imperative that each system has a wide range of height applications depending upon other design and service criteria related to building shape, aspect ratio, architectural functions, load conditions, building stability and site constraints. For each condition, however, there is always an optimum structural system, although it may not necessarily match one of those in the system's tables due to the predominant influence of other factors on the building form. The height limits shown are therefore presumptive based on experience and the authors' prediction within an acceptable range of aspect ratios of the buildings, say about 6 to 8. On occasions, an exterior structure may be combined with an interior one, such as when a tubular frame is also braced or provided with core-supported outriggers and belt trusses, to enhance the building's stiffness.

\section{Interior Structures}

The two basic types of lateral load-resisting systems in the category of interior structures are the moment-resisting frames and shear trusses/ shear walls. These systems are usually arranged as planar assemblies in two principal orthogonal directions and may be employed together as a combined system in which they interact. Another very important system in this category is the core-supported outrigger structure, which is very widely used for supertall buildings at this writing.

The moment-resisting frame (MRF) consists of horizontal (girder) and vertical (column) members rigidly connected together in a planar grid form. Such frames resist load primarily through the flexural stiffness of the members (Kowalczyk, Sinn, \& Kilmister, 1995). The size of the columns is mainly controlled by the gravity loads that accumulate towards the base of the building giving rise to progressively larger column sizes towards the base from the roof. The size of the girders, on the other hand, is controlled by stiffness of the frame in order to ensure acceptable lateral sway of the building. Although gravity load is more or less the same in all typical floors of a tall building, the girder sizes need to be increased to increase the frame stiffness. Likewise, columns already sized for gravity loads need to be slightly increased to increase the frame stiffness as well. MRFs can be located in or around the core, on the exterior, and throughout the interior of the building along grid lines.

Braced frames are laterally supported by vertical steel trusses, also called shear trusses, which resist lateral loads primarily through axial 
Table 2-1: Interior Structures.

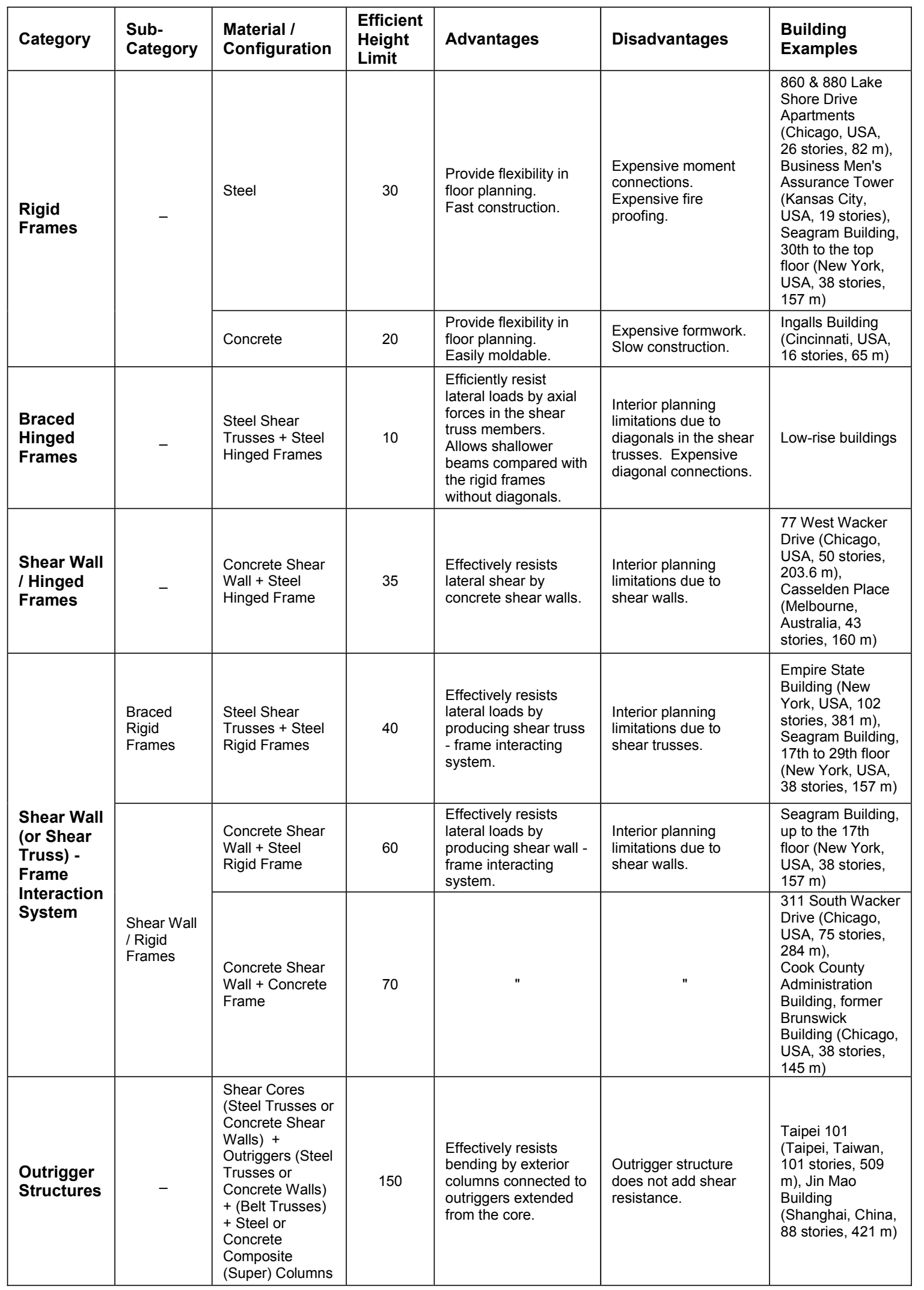

stiffness of the members. These act as vertical cantilever trusses where the columns act as chord members and the concentric $\mathrm{K}, \mathrm{V}$, or X braces act as web members. Such systems are called concentric braced frames $(\mathrm{CBF})$. Eccentric braced frames $(\mathrm{EBF})$ have, on the other hand, braces which are connected to the floor girders that form horizontal elements of the truss, with axial offsets to introduce flexure and shear into the frame (Popov, 1982). This lowers stiffnessto-weight ratio but increases ductility and therefore EBFs are used for seismic zones where ductility is an essential requirement of structural design. EBFs can also be used to accommodate wide 
Table 2-2: Exterior Structures.

\begin{tabular}{|c|c|c|c|c|c|c|}
\hline Category & $\begin{array}{l}\text { Sub } \\
\text { Category }\end{array}$ & $\begin{array}{l}\text { Material / } \\
\text { Configuration }\end{array}$ & $\begin{array}{l}\text { Efficient } \\
\text { Height } \\
\text { Limit }\end{array}$ & Advantages & Disadvantages & $\begin{array}{l}\text { Building } \\
\text { Examples }\end{array}$ \\
\hline \multirow{7}{*}{ Tube } & \multirow{2}{*}{$\begin{array}{l}\text { Framed } \\
\text { Tube }\end{array}$} & Steel & 80 & $\begin{array}{l}\text { Efficiently resists } \\
\text { lateral loads by } \\
\text { locating lateral } \\
\text { systems at the } \\
\text { building perimeter. }\end{array}$ & $\begin{array}{l}\text { Shear lag hinders } \\
\text { true tubular behavior. } \\
\text { Narrow column } \\
\text { spacing obstructs the } \\
\text { view. }\end{array}$ & $\begin{array}{l}\text { Aon Center } \\
\text { (Chicago, USA, } \\
83 \text { stories, } 346 \\
\text { m) }\end{array}$ \\
\hline & & Concrete & 60 & $"$ & $"$ & $\begin{array}{l}\text { Water Tower } \\
\text { Place (Chicago, } \\
\text { USA, } 74 \text { stories, } \\
262 \mathrm{~m} \text { ) }\end{array}$ \\
\hline & \multirow[t]{2}{*}{$\begin{array}{l}\text { Braced } \\
\text { Tube }\end{array}$} & Steel & $\begin{array}{l}100 \\
\text { (With } \\
\text { Interior } \\
\text { Columns) } \\
-150 \\
\text { (Without } \\
\text { Interior } \\
\text { Columns) }\end{array}$ & $\begin{array}{l}\text { Efficiently resists } \\
\text { lateral shear by axial } \\
\text { forces in the } \\
\text { diagonal members. } \\
\text { Wider column } \\
\text { spacing possible } \\
\text { compared with } \\
\text { framed tubes. } \\
\text { Reduced shear lag. }\end{array}$ & $\begin{array}{l}\text { Bracings obstruct the } \\
\text { view. }\end{array}$ & $\begin{array}{l}\text { John Hancock } \\
\text { Center (Chicago, } \\
\text { USA, } 100 \text { stories } \\
344 \mathrm{~m})\end{array}$ \\
\hline & & Concrete & 100 & 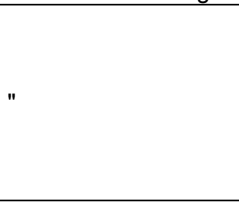 & $"$ & $\begin{array}{l}\text { Onterie Center } \\
\text { (Chicago, } 58 \\
\text { stories, } 174 \mathrm{~m} \text { ), } \\
780 \text { Third } \\
\text { Avenue (New } \\
\text { York, USA, } 50 \\
\text { stories, } 174 \mathrm{~m} \text { ) } \\
\end{array}$ \\
\hline & \multirow{2}{*}{$\begin{array}{l}\text { Bundled } \\
\text { Tube }\end{array}$} & Steel & 110 & Reduced shear lag. & $\begin{array}{l}\text { Interior planning } \\
\text { limitations due to the } \\
\text { bundled tube } \\
\text { configuration. }\end{array}$ & $\begin{array}{l}\text { Sears Tower } \\
\text { (Chicago, USA, } \\
108 \text { stories, } 442 \\
\text { m) }\end{array}$ \\
\hline & & Concrete & 110 & $"$ & $"$ & $\begin{array}{l}\text { Carnegie Hall } \\
\text { Tower (New } \\
\text { York, USA, } 62 \\
\text { stories, } 230.7 \mathrm{~m} \text { ) }\end{array}$ \\
\hline & $\begin{array}{l}\text { Tube in } \\
\text { Tube }\end{array}$ & $\begin{array}{l}\text { Ext. Framed } \\
\text { Tube (Steel or } \\
\text { Concrete) }+ \text { Int. } \\
\text { Core Tube (Steel } \\
\text { or Concrete) }\end{array}$ & 80 & $\begin{array}{l}\text { Effectively resists } \\
\text { lateral loads by } \\
\text { producing interior } \\
\text { shear core - exterior } \\
\text { framed tube } \\
\text { interacting system. }\end{array}$ & $\begin{array}{l}\text { Interior planning } \\
\text { limitations due to } \\
\text { shear core. }\end{array}$ & $\begin{array}{l}181 \text { West } \\
\text { Madison Street } \\
\text { (Chicago, USA, } \\
50 \text { stories, } 207 \\
\text { m) }\end{array}$ \\
\hline \multirow[t]{2}{*}{ Diagrid } & \multirow[t]{2}{*}{-} & Steel & 100 & $\begin{array}{l}\text { Efficiently resists } \\
\text { lateral shear by axial } \\
\text { forces in the } \\
\text { diagonal members. }\end{array}$ & Complicated joints. & $\begin{array}{l}\text { Hearst Building } \\
\text { (New York, USA, } \\
42 \text { stories, } 182 \\
\text { m), } 30 \text { St Mary } \\
\text { Axe, also known } \\
\text { as Swiss Re } \\
\text { Building } \\
\text { (London, UK, } 41 \\
\text { stories, } 181 \mathrm{~m} \text { ) } \\
\end{array}$ \\
\hline & & Concrete & 60 & $"$ & $\begin{array}{l}\text { Expensive formwork. } \\
\text { Slow construction. }\end{array}$ & $\begin{array}{l}\text { O-14 Building } \\
\text { (Dubai) }\end{array}$ \\
\hline $\begin{array}{l}\text { Space Truss } \\
\text { Structures }\end{array}$ & - & Steel & 150 & $\begin{array}{l}\text { Efficiently resists } \\
\text { lateral shear by axial } \\
\text { forces in the space } \\
\text { truss members. }\end{array}$ & $\begin{array}{l}\text { Obstruct the view. } \\
\text { May obstruct the } \\
\text { view. }\end{array}$ & $\begin{array}{l}\text { Bank of China } \\
\text { (Hong Kong, } \\
\text { China, } 72 \\
\text { stories, } 367 \mathrm{~m} \text { ) }\end{array}$ \\
\hline \multirow[t]{2}{*}{ Superframes } & \multirow{2}{*}{-} & Steel & 160 & $\begin{array}{l}\text { Could produce } \\
\text { supertall buildings. }\end{array}$ & $\begin{array}{l}\text { Building form } \\
\text { depends to a great } \\
\text { degree on the } \\
\text { structural system. }\end{array}$ & $\begin{array}{l}\text { Chicago World } \\
\text { Trade Center } \\
\text { (Chicago, USA, } \\
168 \text { stories, } \\
\text { Unbuilt) }\end{array}$ \\
\hline & & Concrete & 100 & $"$ & 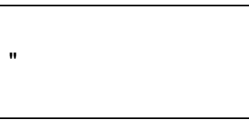 & $\begin{array}{l}\text { Parque Central } \\
\text { Tower (Caracas, } \\
\text { Venezuela, } 56 \\
\text { stories, } 221 \mathrm{~m} \text { ) }\end{array}$ \\
\hline $\begin{array}{l}\text { Exo- } \\
\text { skeleton }\end{array}$ & - & Steel & 100 & $\begin{array}{l}\text { Interior floor is never } \\
\text { obstructed by } \\
\text { perimeter columns. }\end{array}$ & $\begin{array}{l}\text { Thermal expansion / } \\
\text { contraction. } \\
\text { Systemic thermal } \\
\text { bridges. }\end{array}$ & $\begin{array}{l}\text { Hotel de las } \\
\text { Artes } \\
\text { (Barcelona, } \\
\text { Spain, } 43 \\
\text { stories, } 137 \mathrm{~m} \text { ) }\end{array}$ \\
\hline
\end{tabular}

doors and other openings, and have on occasions been used for non-seismic zones (Corrin \& Swensson, 1992). Braced frames are generally located in the service and elevator core areas of tall buildings. The frame diagonals are enclosed within the walls.

Reinforced concrete planar solid or coupled shear walls have been one of the most popular systems used for high-rise construction to resist lateral forces caused by wind and earthquakes. They are treated as vertical cantilevers fixed at the base. When two or more shear walls in the same plane are interconnected by beams or slabs, as is the case with shear walls with door or window openings, the total 
stiffness of the system exceeds the sum of the individual wall stiffnesses. This is so because the connecting beam forces the walls to act as a single unit by restraining their individual cantilever actions. These are known as coupled shear walls. Shear walls used in tall office buildings are generally located around service and elevator cores, and stairwells. In fact, in many tall buildings, the vertical solid core walls that enclose the building services can be used to stabilize and stiffen the building against lateral loads. Many possibilities exist with single or multiple cores in a tall building with regard to their location, shape, number, and arrangement. The core walls are essentially shear walls that can be analyzed as planar elements in each principal direction or as threedimensional elements using computer programs.

Rigid frames may be combined with vertical steel trusses or reinforced concrete shear walls to create shear wall (or shear truss)-frame interaction systems. Rigid frame systems are not efficient for buildings over 30 stories in height because the shear racking component of deflection caused by the bending of columns and girders causes the building to sway excessively. On the other hand, vertical steel shear trusses or concrete shear walls alone may provide resistance for buildings up to about 10 or 35 stories, respectively, depending on the height-to-width ratio of the system (see Table 2-1). When shear trusses or shear walls are combined with MRFs, a shear truss (or shear wall)-frame interaction system results. The approximately linear shear-type deflected profile of the MRF, when combined with the parabolic cantilever sway mode of the shear truss or shear walls,

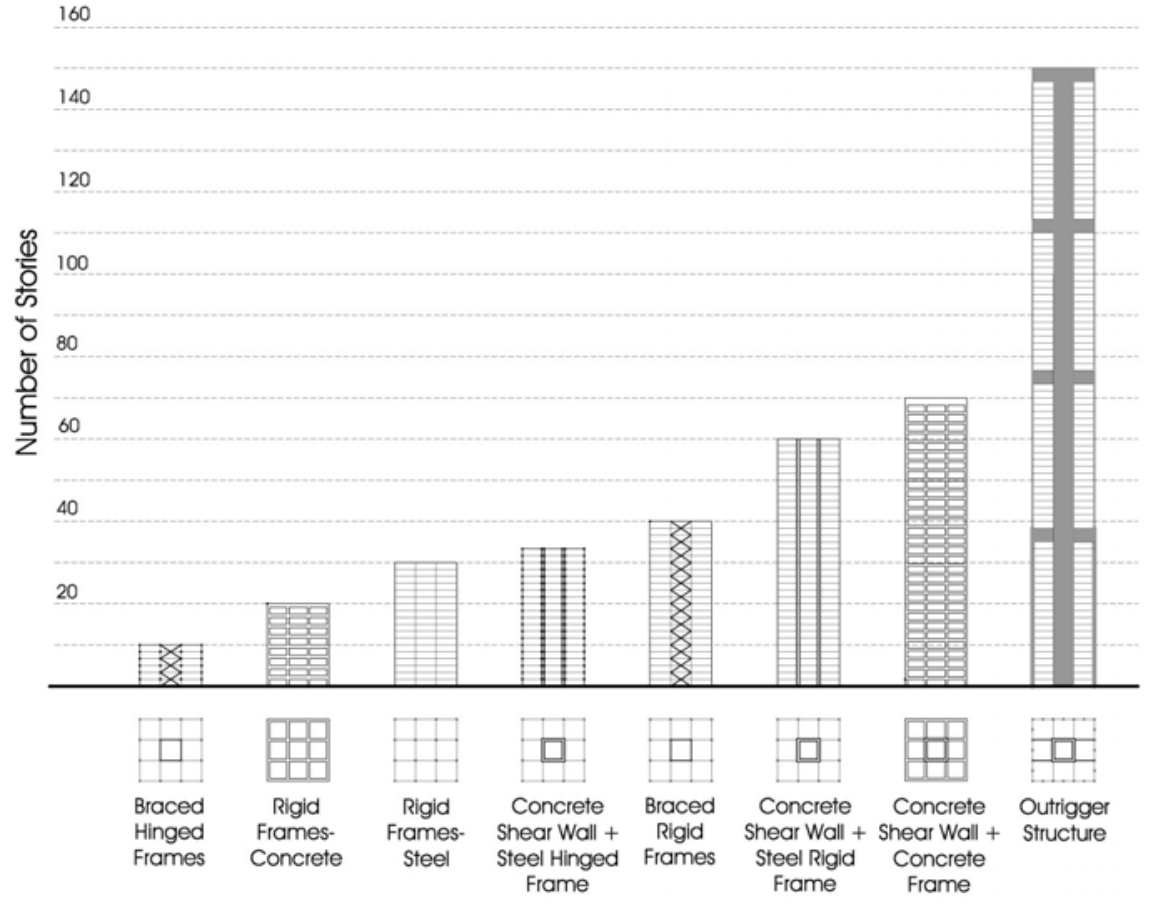

Figure 4-1: Interior structures.

results in a common shape of the structure when the two systems are forced to deflect in the same way by the rigid floor diaphragm. The upper part of the truss is restrained by the frame, whereas at the lower part, the shear wall or truss restrains the frame (Figure 5). This effect produces increased lateral rigidity of the building. This type of system has wide applications for buildings up to about 40 to 70 stories in height. A "milestone" paper by Khan and Sbarounis (1964) presented the mechanics of a shear wall-frame interaction system that led to the development of innovative structural systems that are cost-effective (Ali, 2001).

Outrigger systems have been historically used by sailing ships to

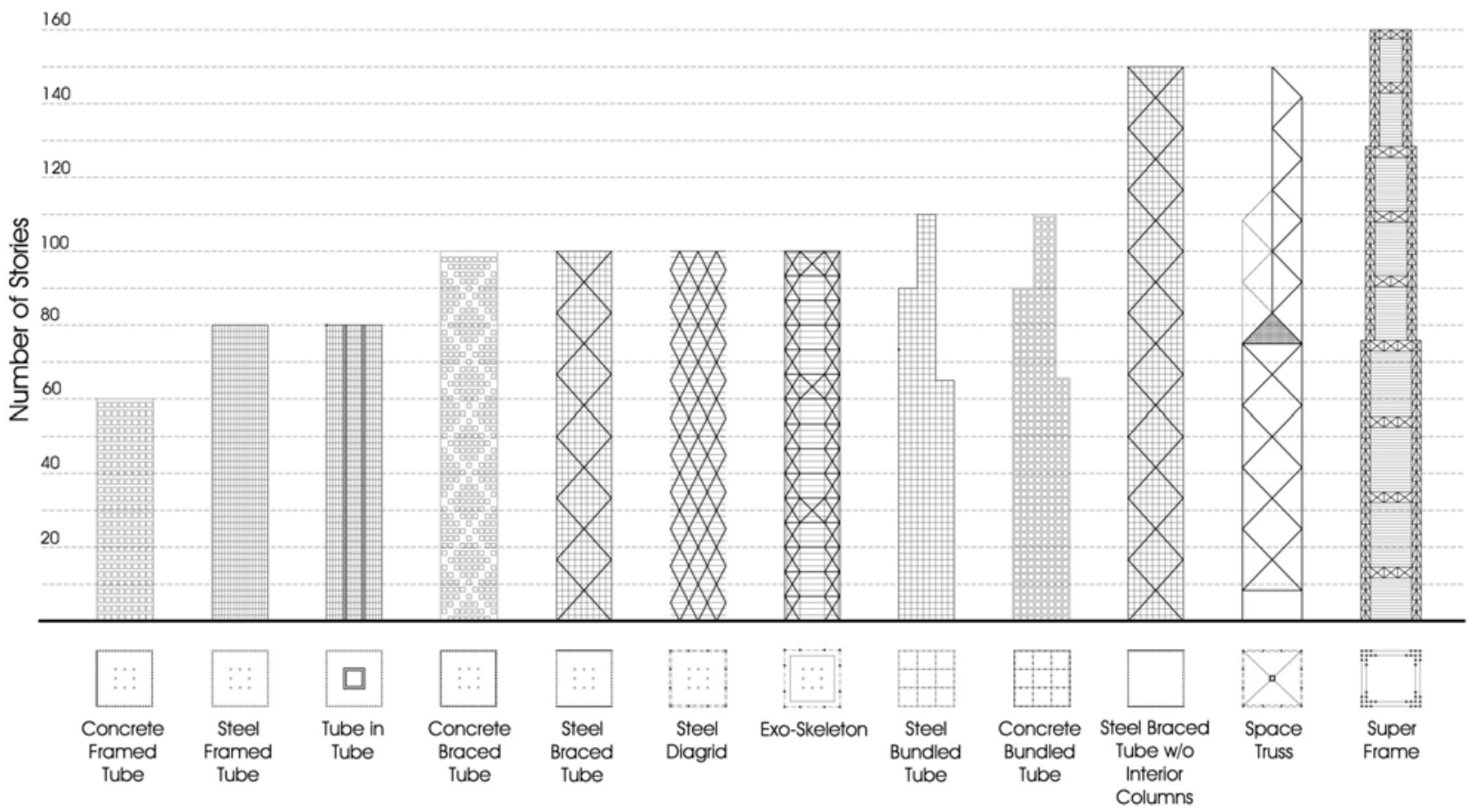

Figure 4-2: Exterior structures. 


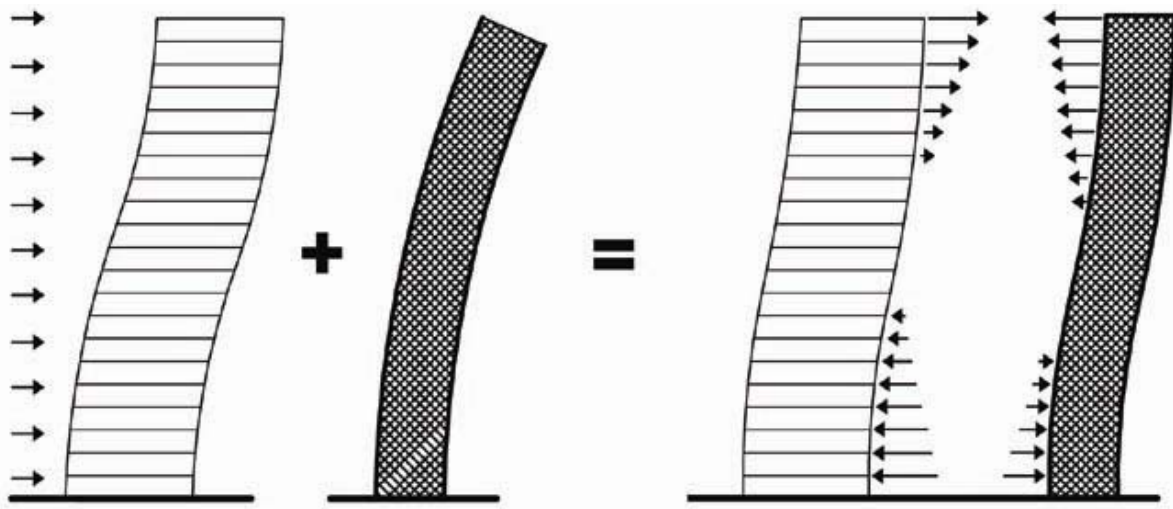

Figure 5: Shear wall (or shear truss)-frame interaction system.

or reinforced concrete core walls are generally effective for resisting lateral loads. However, for greater heights, the resistance of the core systems to bending caused by overturning becomes progressively inefficient. Moreover, a core system with its highly slender attribute can generate excessive uplift forces in the core columns and high overturning forces on the foundation system. In reinforced concrete cores, excessive wall elements where large net tensile forces develop can easily cancel the inherent efficiency of concrete in compression. Likewise, in steel cores, excessive welded or

help resist the wind forces in their sails, making the tall and slender masts stable and strong. The core in a tall building is analogous to the mast of the ship, with outriggers acting as the spreaders and the exterior columns like the stays. As for the sailing ships, outriggers serve to reduce the overturning moment in the core that would otherwise act as pure cantilever, and to transfer the reduced moment to the outer columns through the outriggers connecting the core to these columns (Figure 6). The core may be centrally located with outriggers extending on both sides or in some cases it may be located on one side of the building with outriggers extending to the building columns on the other side (Taranath, 1998).

The outriggers are generally in the form of trusses in steel structures, or walls in concrete structures, that effectively act as stiff headers inducing a tension-compression couple in the outer columns. Belt trusses are often provided to distribute these tensile and compressive forces to a large number of exterior frame columns. The belt trusses also help in minimizing differential elongation and shortening of columns. Outriggers can also be supported on megacolumns in the perimeter of the building. Although this structure is primarily an interior system, the belt trusses or megacolumns offer a wider perimeter, thus resisting the lateral push of the building's 'feet' spread.

For buildings between about 30 to 70 stories, steel braced cores bolted tensile splices could greatly reduce the ease of erection and fabrication. The core-outrigger system alleviates this problem.

Some other advantages of the core-and-outrigger system are that the exterior column spacing can easily meet aesthetic and functional requirements, and the building's perimeter framing system may consist of simple beam-column framing without the need for rigid-frame-type connections. For supertall buildings, connecting the outriggers with exterior megacolumns opens up the façade system for flexible aesthetic and architectural articulation thereby overcoming a principal drawback of closed-form tubular systems. In addition, outrigger systems have a great height potential up to 150 stories and possibly more.

The principal disadvantages are that the outriggers interfere with the occupiable or rentable space and the lack of repetitive nature of the structural framing results in a negative impact on the erection process. However, these drawbacks can be overcome by careful architectural and structural planning such as placing outriggers in mechanical floors and development of clear erection guidelines.

The outrigger systems may be formed in any combination of steel, concrete and composite construction. Because of the many functional benefits of outrigger systems and the advantages outlined above, this system has lately been very popular for supertall buildings all over the world. A very early example of outrigger structure can
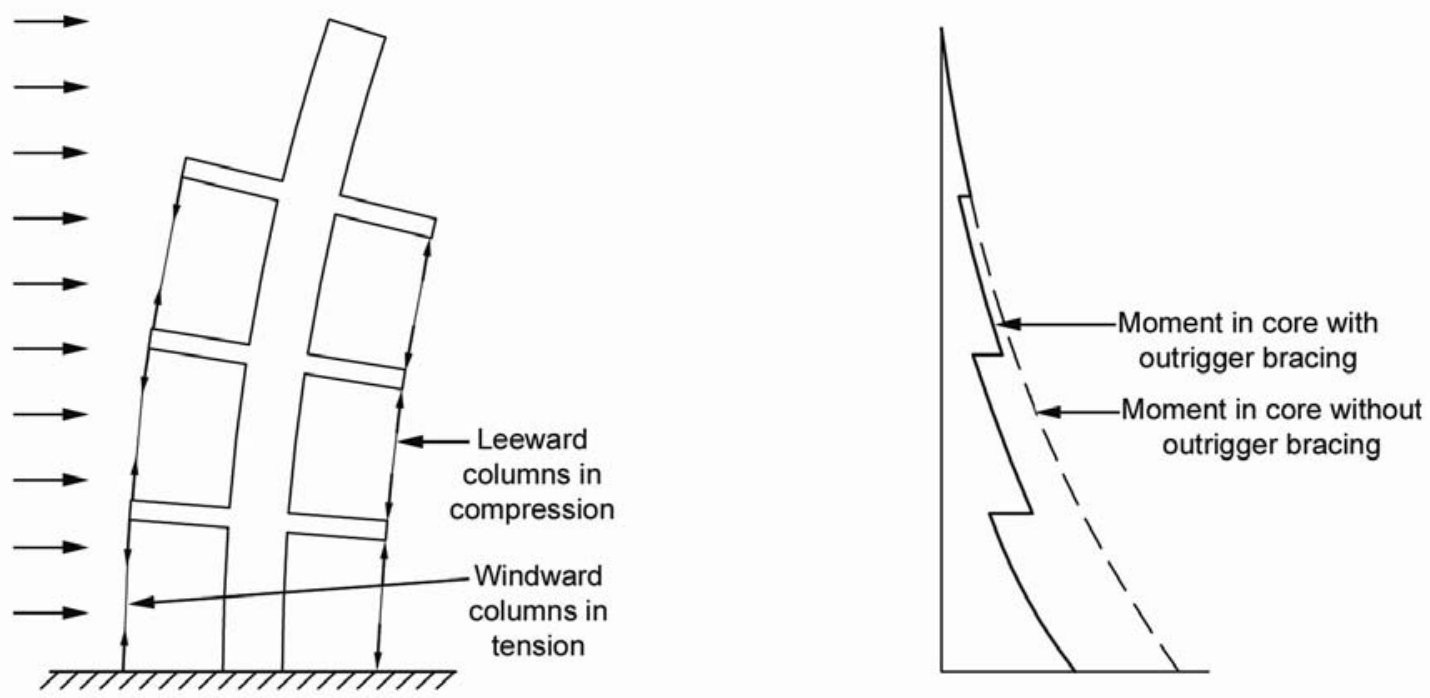

Figure 6: Core-supported outrigger structures. 


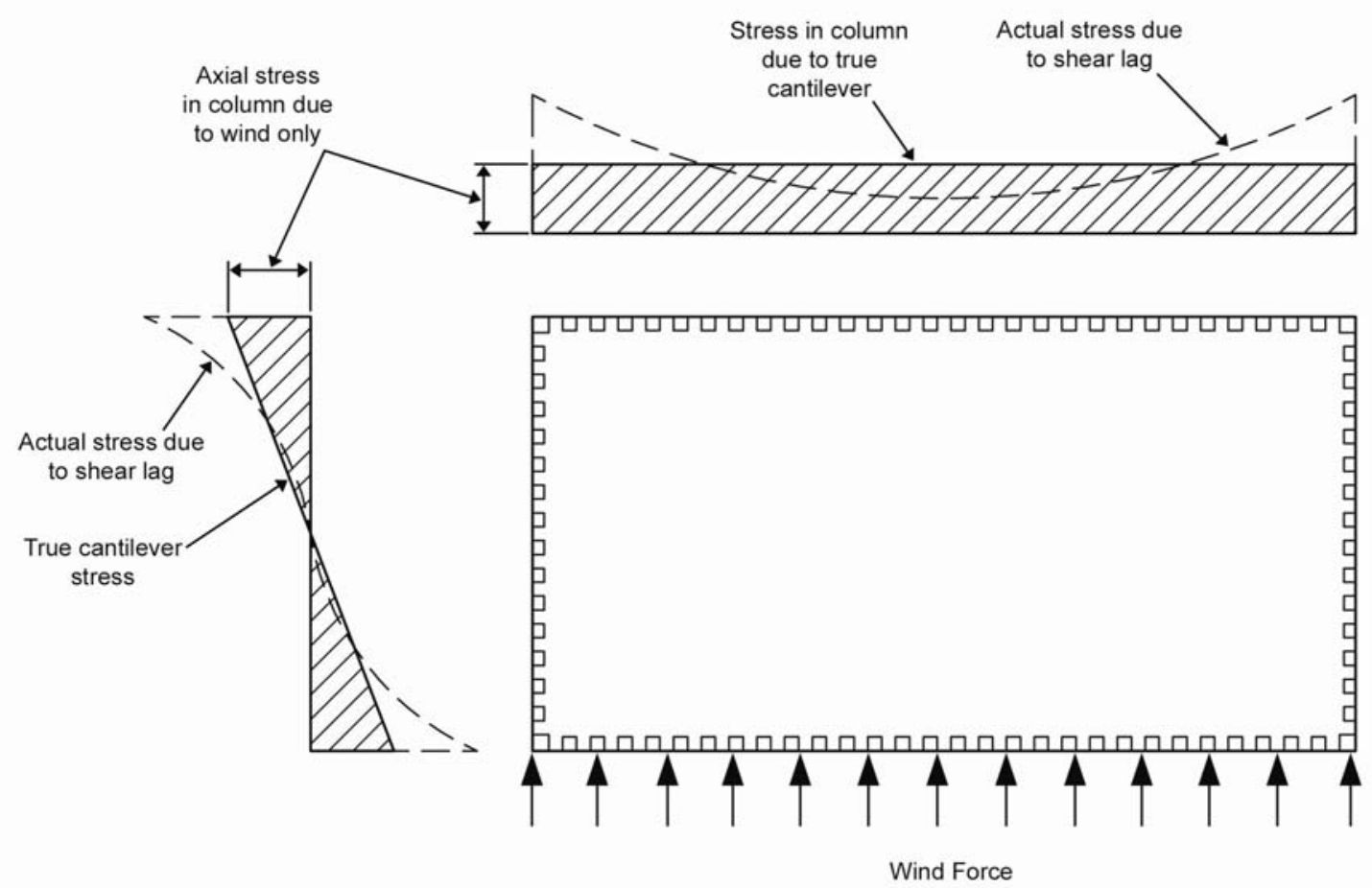

Figure 7: Shear lag.

be found in the Place Victoria Office Tower of 1965 in Montreal designed by Nervi and Moretti. It was also used by Fazlur Khan in the 42-story First Wisconsin Center of 1973 in Milwaukee, Wisconsin. However, major application of this structural system can be seen on contemporary skyscrapers such as the Jin Mao Building in Shanghai and the Taipei 101 Tower in Taipei.

\section{Exterior Structures}

The nature of building perimeters has more structural significance in tall buildings than in any other building type due to their very tallness, which means greater vulnerability to lateral forces, especially wind loads. Thus, it is quite desirable to concentrate as much lateral load-resisting system components as possible on the perimeter of tall buildings to increase their structural depth, and, in turn, their resistance to lateral loads.

One of the most typical exterior structures is the tube, which can be defined as a three-dimensional structural system utilizing the entire building perimeter to resist lateral loads. The earliest application of the tubular notion is attributed to Fazlur Khan, who thought of this concept in 1961 (Ali, 2001) and designed the 43-story DeWitt-Chestnut Apartment Building in Chicago, completed in 1965, the first known building designed as a framed tube. A few other world's tallest buildings using this concept are the 110-story Sears Tower, the 100-story John Hancock Center, and the 83-story Amoco building, all in Chicago, and the 110story World Trade Center Towers (destroyed in 2001 by a terrorist attack) in New York. Many other recent buildings in excess of 50 stories have employed the tubular concept or a variation of it. The introduction of tube systems has been revolutionary since for the first time the three-dimensional response of buildings was directly exploited to advantage departing from the conventional rigid frame system consisting of rigidly connected planar beam-column grids. Tubular forms have several types depending upon the structural efficiency that they can provide for different heights.

In a framed tube system, which is the basic tubular form, the building has closely spaced columns and deep spandrel beams rigidly connected together throughout the exterior frames. Depending upon the structural geometry and proportions, exterior column spacing should be from 5 to $15 \mathrm{ft}$ ( 1.5 to $4.5 \mathrm{~m})$ on centers. Practical spandrel beam depths should vary from 24 to 48 in $(600$ to $1200 \mathrm{~mm}$ ). The resulting structural organization not only provides a structural expression of the façade, thereby defining the architectural fenestration, but also can cut cost by eliminating the need for mullions of the curtain wall fully or partly. As shown in Figure 7, for a framed tube subjected to lateral loads, the axial forces in the corner columns are the greatest and the distribution is non-linear for both the web frame (i.e., frame parallel to wind), and the flange frame (i.e., frame perpendicular to wind). This is because the axial forces in the columns toward the middle of the flange frames lag behind those near the corner due to the nature of a framed tube which is different from a solid-wall tube. This phenomenon is known as shear lag. The purpose of optimal design of a framed tube is to limit the shear lag effect and aim for more cantilever-type behavior of the structure within reasonable and practical limits (i.e., by achieving a cantilever deflection of 50 to 80 percent of the total lateral sway of the building).

A braced tube is a variation of the framed tube and was first applied on the 100-story John Hancock Center of 1970 in Chicago (Ali, 2001). This concept stems from the fact that instead of using closely spaced perimeter columns, it is possible to stiffen the widely spaced columns by diagonal braces to create wall-like characteristics. The framed tube becomes progressively inefficient over 60 stories since the web frames begin to behave as conventional rigid frames. Consequently, beam and column designs are controlled by bending action, resulting in large size. In addition, the cantilever behavior of the structure is thus undermined and the shear lag effect is aggravated. A braced tube overcomes this problem by stiffening the perimeter frames in their own planes. The braces also collect gravity loads from floors and act as inclined columns. The diagonals of a trussed tube connected to columns at each joint effectively 

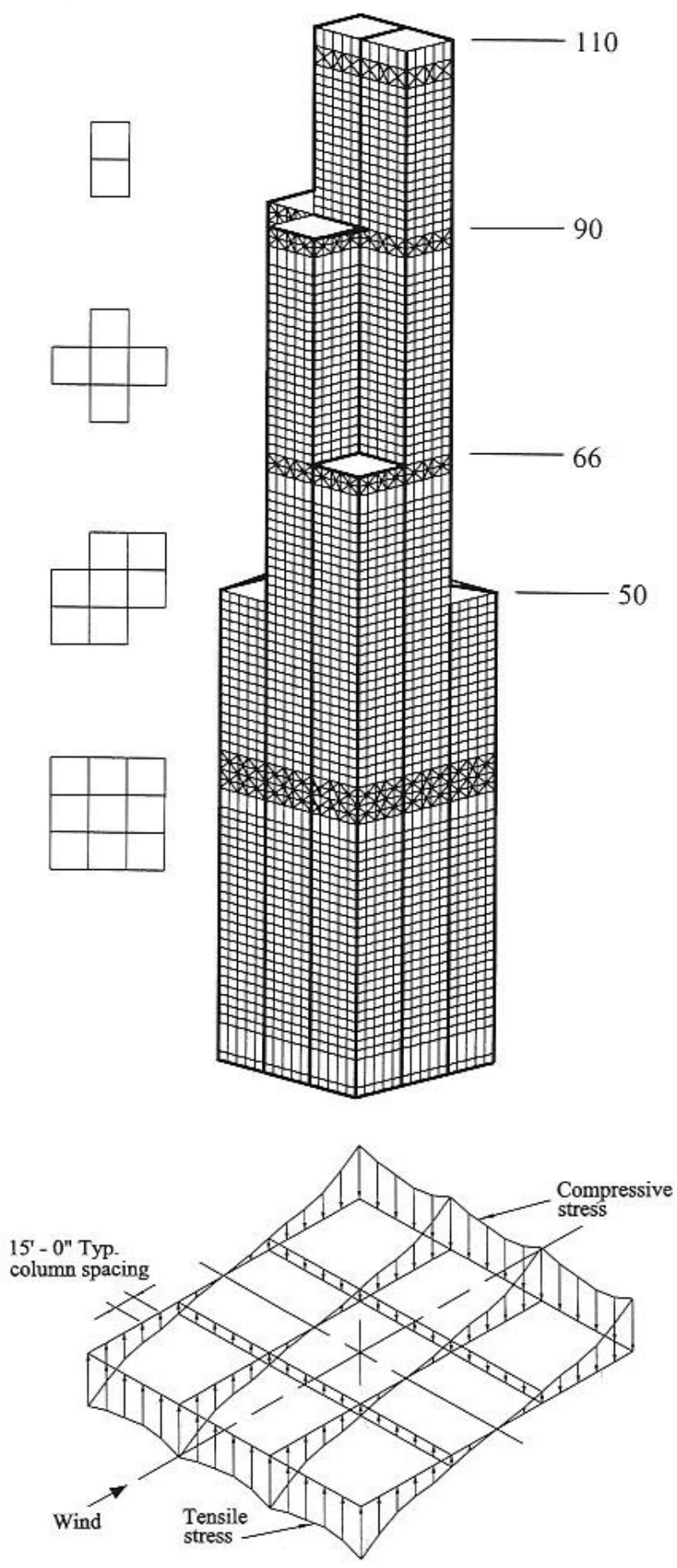

Figure 8: Bundled tube (Sears Tower, Chicago).

eliminate the effects of shear lag throughout the tubular framework. Therefore, the columns can be more widely spaced and the sizes of spandrels and columns can be smaller than those needed for framed tubes, allowing for larger window openings than in the framed tubes (Khan, 1967).

A bundled tube is a cluster of individual tubes connected together to act as a single unit. For very tall structures, a single framed tube is not adequate, since the width of the building at its base should be large to maintain a reasonable slenderness (i.e., height-to-width) ratio such that the building is not excessively flexible and does not sway too much. The system efficiency is considerably diminished in a single framed tube of enormous height due to shear lag effect. For such a structure, the threedimensional response of the structure could be improved for strength and stiffness by providing cross walls or cross frames in the building.

The 110-story Sears Tower completed in 1974 was the first bundled tube structure in which nine steel framed tubes are bundled at the base, some of which are terminated at various levels along the building's height with two tubes continuing between the $90^{\text {th }}$ floor and the roof (Ali, 2001). Such flexibility of organizing the floor areas, from very large at the base to much smaller at the top, gave the bundled tube system an added advantage. The bundled tube concept also allowed for wider column spacing in the tubular walls, which made it possible to place interior frame lines without seriously compromising interior space planning of the building. The bundled tube system thus offers great freedom in the architectural planning by creating a powerful vocabulary for a variety of existing building forms. Figure 8 shows the bundled tube concept as it was applied to the Sears Tower.

A bundled tube building in concrete is One Magnificent Mile of 1983 in Chicago. In this multi-use building, it was possible to assemble the individual tubes in any configuration and terminated at different heights without loss of structural integrity. By carrying the idea of bundled framed tubes further, it is possible to add diagonals to them to increase the efficient height limit. In addition, it is worth noting that to behave as a bundled tube the individual tubes could be of different shapes, such as rectangular, triangular or hexagonal as is demonstrated by this building.

The stiffness of a framed tube can also be enhanced by using the core to resist part of the lateral load resulting in a tube-intube system. The floor diaphragm connecting the core and the outer tube transfer the lateral loads to both systems. The core itself could be made up of a solid tube, a braced tube, or a framed tube. Such a system is called a tube-in-tube, an example of which is the 52-story One Shell Plaza of 1971 in Houston, Texas. It is also possible to introduce more than one tube inside the perimeter tube.

The inner tube in a tube-in-tube structure can act as a second line of defense against a malevolent attack with airplanes or missiles. For example, a solid concrete core in the World Trade Center in New York could probably have saved many lives of those who were trapped in fire above the levels of airplane impact.

Another type of exterior structure is a diagrid system. With their structural efficiency as a varied version of the tubular systems, diagrid structures have been emerging as a new aesthetic trend for tall buildings in this era of pluralistic styles. Early designs of tall buildings recognized the effectiveness of diagonal bracing members in resisting lateral forces. Most of the structural systems deployed for early tall buildings were steel frames with diagonal bracings of various configurations such as $\mathrm{X}, \mathrm{K}$, and chevron. However, while the structural importance of diagonals was well recognized, the aesthetic potential of them was not appreciated since they were considered obstructive for viewing the outdoors. Thus, diagonals were generally embedded within the building cores which were usually located in the interior of the building.

A major departure from this design approach occurred when braced tubular structures were introduced in the late 1960s. For the 100-story tall John Hancock Center in Chicago, the diagonals were located along the entire exterior perimeter surfaces of the 
building in order to maximize their structural effectiveness and capitalize on the aesthetic innovation. This strategy is much more effective than confining diagonals to narrower building cores. Despite the clear symbiosis between structural action and aesthetic intent of the Hancock Tower, this overall design approach has not emerged as the sole aesthetic preference of architects. However, recently the use of perimeter diagonals - thus the term "diagrid" - for structural effectiveness and lattice-like aesthetics has generated renewed interest in architectural and structural designers of tall buildings.

The difference between conventional exterior-braced frame structures and current diagrid structures is that, for diagrid structures, almost all the conventional vertical columns are eliminated. This is possible because the diagonal members in diagrid structural systems can carry gravity loads as well as lateral forces due to their triangulated configuration in a distributive and uniform manner. Compared with conventional framed tubular structures without diagonals, diagrid structures are much more effective in minimizing shear deformation because they carry shear by axial action of the diagonal members, while conventional tubular structures carry shear by the bending of the vertical columns and horizontal spandrels (Moon, 2005).

The diagrid can be compared with another prevalent structural system, the outrigger structures. Properly designed, an outrigger structure is effective in reducing the overturning moment and drift of the building. However, the addition of the outrigger trusses between the shear core and exterior columns does not add lateral shear rigidity to the core. Thus, tall buildings that employ outrigger systems still require cores having significant shear rigidity. The diagrid structure provides both bending and shear rigidity. Thus, unlike outrigger structures, diagrid structures do not need high shear rigidity cores because shear can be carried by the diagrids located on the perimeter, even though supertall buildings with a diagrid system can be further strengthened and stiffened by engaging the core, generating a system similar to a tube-in-tube.

An early example of today's diagrid-like structure is the IBM Building of 1963 in Pittsburgh. With its 13-story building height, this building was not given much attention by architects and engineers, and it was not designed as a three-dimensional system as is done at present. In the early 1980s Humana Headquarters competition, a diagrid structure was proposed by Sir Norman Foster. However, the winning entry at that time was a historicist building of the post-modern style designed by Michael Graves. Only recently have notable diagrid tall buildings been commissioned. Examples are the 30 St. Mary Axe in London - also known as the Swiss Re Building (Figure 9) - and the Hearst Headquarters in New York, both by Sir Norman Foster, and Guangzhou Twin Towers in Guangzhou by Wilkinson Eyre. Another ultra-tall building currently being designed by Skidmore, Owings and Merrill is the Lotte Super Tower in Korea, which employs a diagrid multi-planar façade.

While the example diagrids presented so far are steel structures, which clearly express their regular diagrids on their facades, another new design approach uses reinforced concrete, creating new architectural aesthetic expressions different from that generated by steel structures. Both the COR Building in Miami (Figure 10) by Chad Oppenheim Architecture and Ysrael Seinuk of YAS Consulting Engineers and the O-14 Building in Dubai

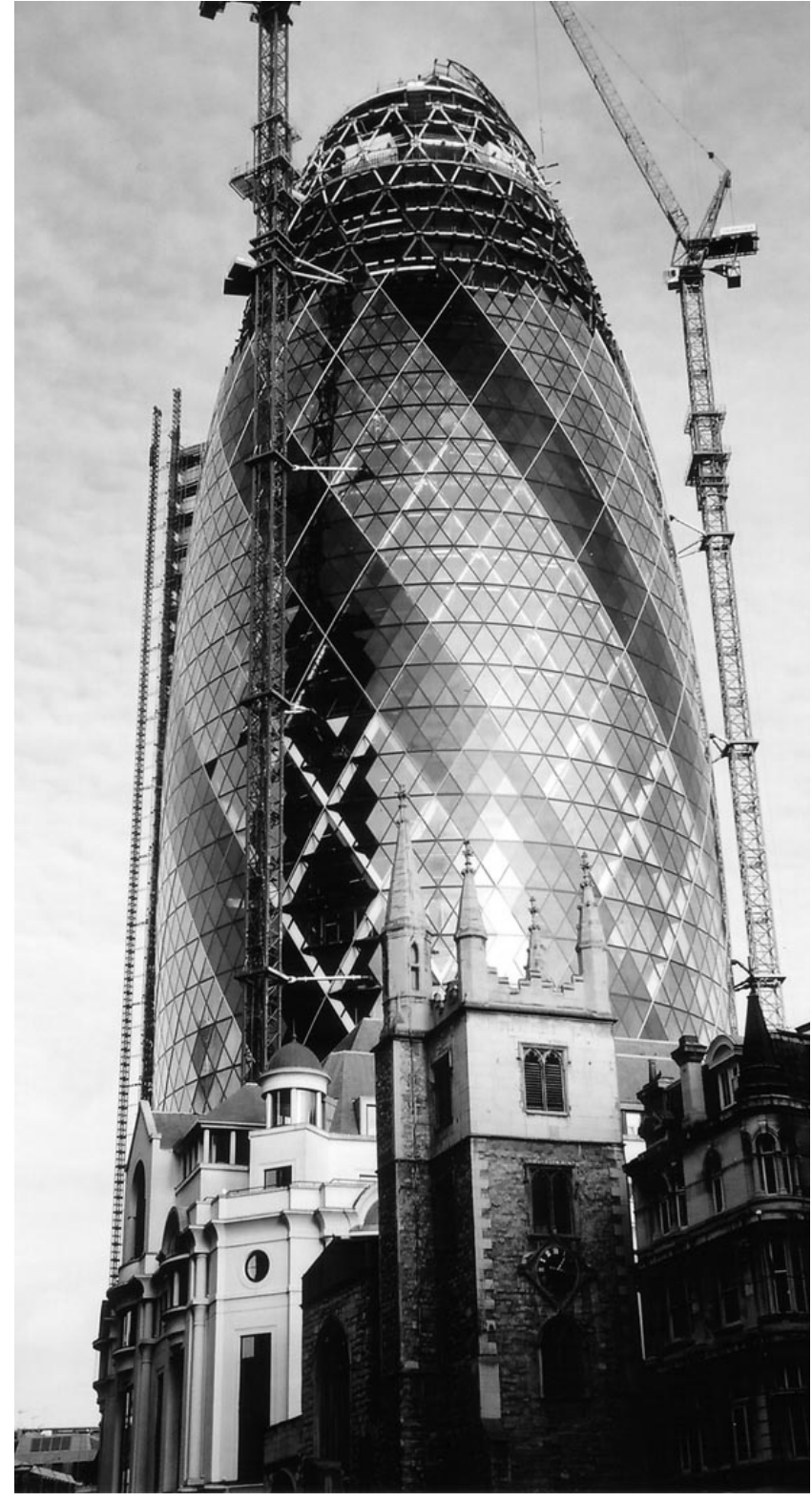

Figure 9: 30 St. Mary Axe during construction (Courtesy of John E. Fernandez).

(Figure 11) by RUR Architecture employ reinforced concrete diagrids as their primary lateral load-resisting systems. Due to the properties of concrete, the structural diagrid patterns, which are directly expressed as building façade aesthetics, are more fluid and irregular in these buildings, and different from the explicit and pristine features of steel diagrids.

Other types of lateral load-resisting systems in the category of exterior structures include space trusses, super frames and exoskeleton. These have been occasionally used for tall buildings. Space truss structures are modified braced tubes with diagonals connecting the exterior to interior. In a typical braced tube structure, all the diagonals, which connect the chord members - vertical corner columns in general, are located on the plane parallel to the facades. However, in space trusses, some diagonals penetrate the interior of the building. Examples include the Bank of China Tower of 1990 by I. M. Pei in Hong Kong.

A superframe is composed of megacolumns comprising braced frames of large dimensions at building corners, linked by 


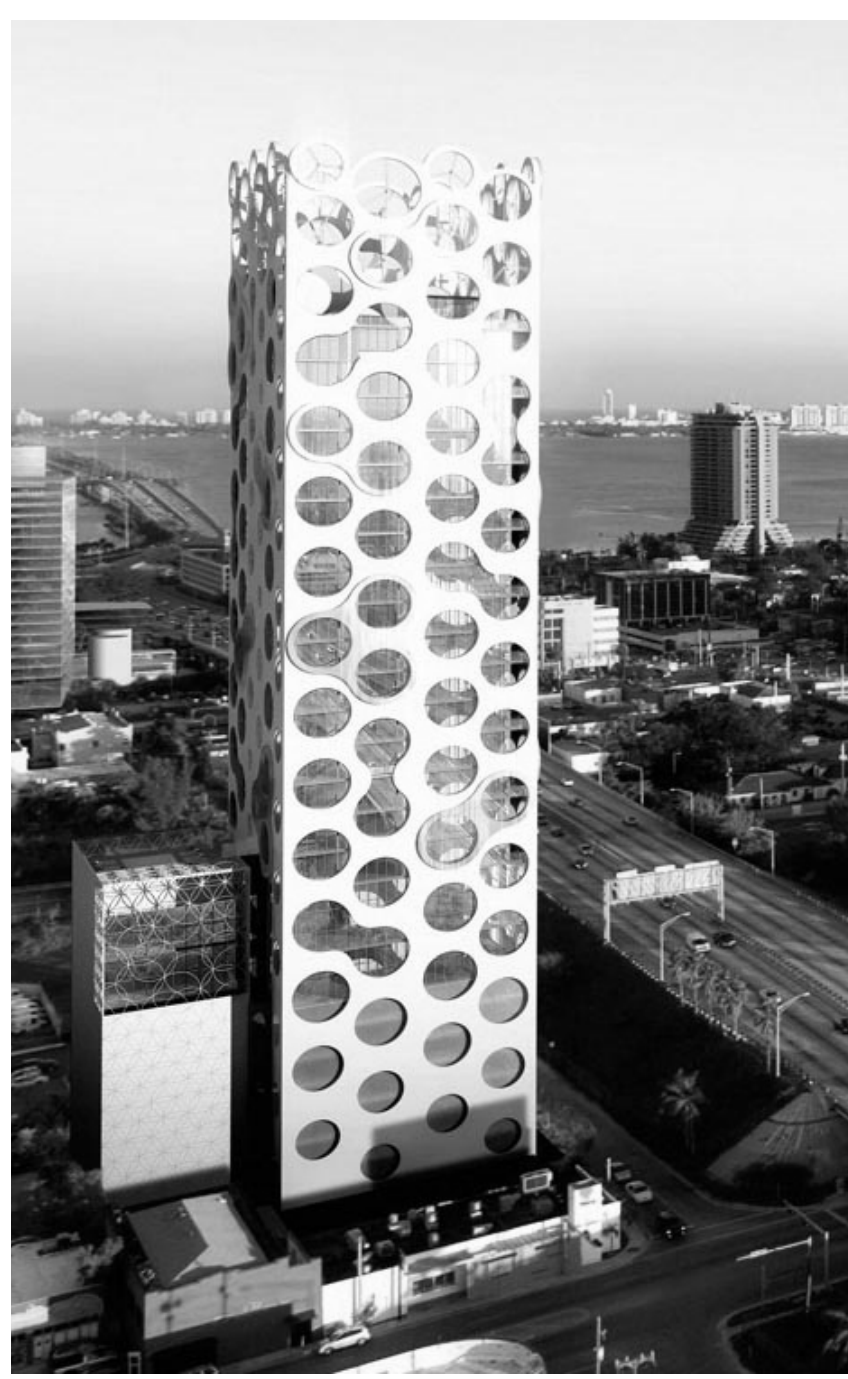

Figure 10: COR Building

(Courtesy of Chad Oppenheim and dbox).

multistory trusses at about every 15 to 20 stories. The concept of superframe can be used in various ways for tall buildings, such as the 56-story tall Parque Central Complex Towers of 1979 in Caracas, Venezuela and the 168-story tall Chicago World Trade Center proposed by Fazlur Khan in 1982 (Ali, 2001; Iyengar, 1986).

In exoskeleton structures, lateral load-resisting systems are placed outside the building lines away from their facades. Examples include Hotel de las Artes in Barcelona. Due to the system's compositional characteristics, it acts as a primary building identifier - one of the major roles of building facades in general cases. Fire proofing of the system is not a serious issue due to its location outside the building line. However, thermal expansion/contraction of the system, exposed to the ever-changing outdoor weather, and the systemic thermal bridges should be carefully considered during design.

\section{Damping Strategies for Structural Systems}

The direction of the evolution of tall building structural systems, based on new structural concepts with newly adopted high-strength materials and construction methods, has been towards augmented efficiency. Consequently, tall building structural systems have become much lighter than earlier ones. This direction of the structural evolution toward lightness, however,

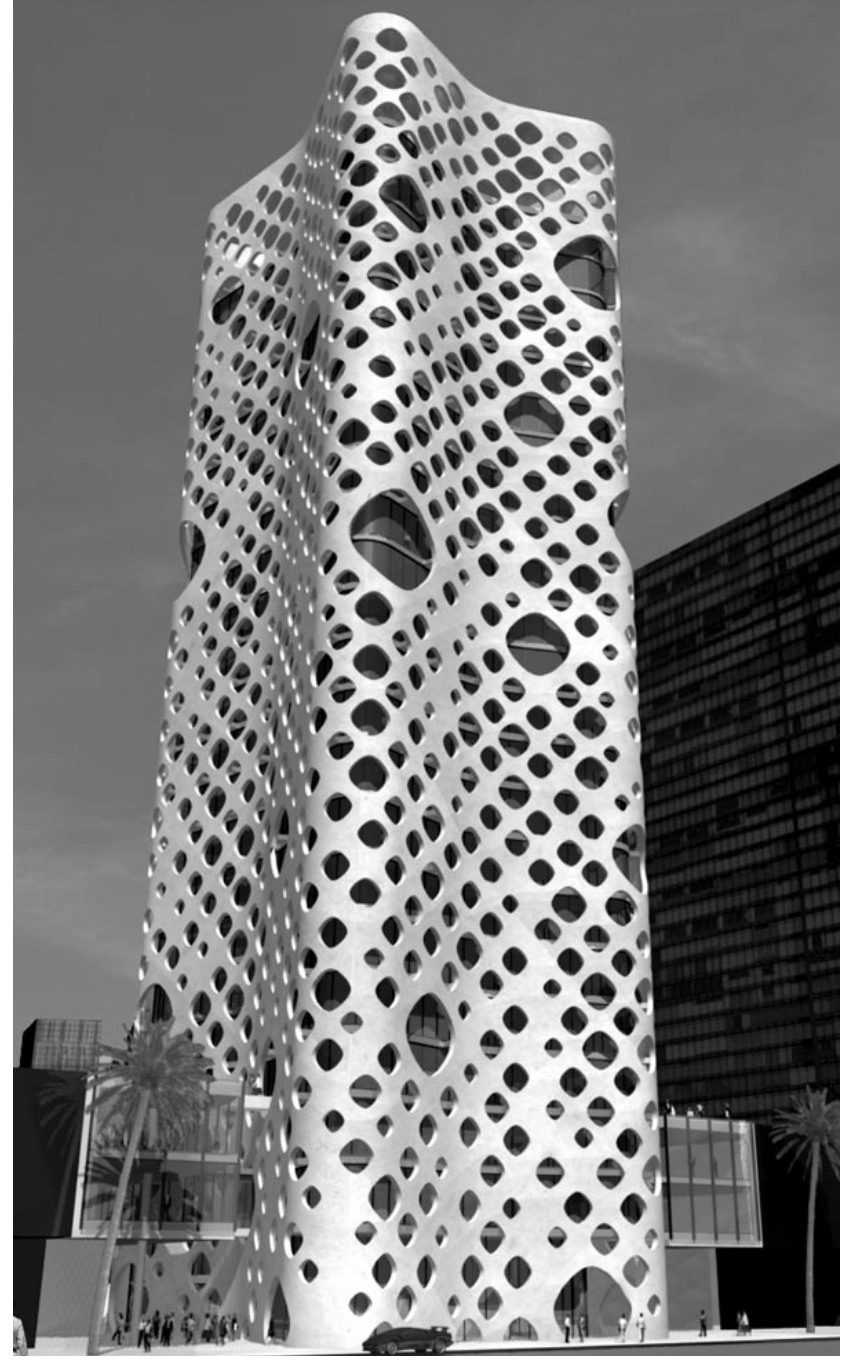

Figure 11: O-14 Building

(Courtesy of Jesse Reiser, RUR Architecture).

often causes serious structural motion problems - primarily due to wind-induced motion.

From the viewpoint of structural material's properties, due to the lag in material stiffness compared with material strength, the serviceability of the structure potentially becomes a governing factor in tall building design when high strength material is used. For instance, today, structural steel is available from 170 to $690 \mathrm{MPa}$ (24 to $100 \mathrm{ksi}$ ). However, its modulus of elasticity remains nearly the same without regard to the change in its strength. The change of production process or heat treatment influences its strength but not the modulus of elasticity. Regarding concrete, increase in its strength results in increase in its modulus of elasticity, albeit increasing its brittleness. However, this increase in the modulus of elasticity is relatively small compared with the increase in strength. Thus, the lighter structures produced by high-strength materials can cause motion problems.

The control of this structural motion should be considered with regard to static loads as well as dynamic loads. Against the static effect of wind loads, stiffer structures produce less lateral displacement. With regard to the dynamic effect of wind loads, not only the windward response but also the across-wind response of the structure should be considered. Generally, in tall buildings, the lateral vibration in the across-wind direction induced by vortex shedding is more critical than that in the windward direction. 
Regarding both directions, structures with more damping reduce the magnitude of vibration and dissipate the vibration more quickly. With regard to the vibration in the across-wind direction, a stiffer structure reduces the probability of lock-in condition because as a structure's fundamental frequency increases, wind velocity that causes the lock-in condition also increases. Since the natural direction of structural evolution towards lightness is not likely to be reversed in the future, more stiffness and damping characteristics should be achieved with a minimum amount of material (Moon, 2005).

Achievement of more stiffness in tall buildings is related to the configuration of primary structural systems, which were discussed in previous sections. For example, more recent structural trends such as tubes, diagrids and coresupported outrigger structures in general achieve much higher stiffness than traditional rigid frame structures. Obtaining more damping is also related to the choice of primary structural systems and materials. However, the damping achieved by the primary structure is quite uncertain until the building construction is completed. A more rigorous and reliable increase in damping, to resolve tall building motion problems, could be achieved by installing auxiliary damping devices within the primary structural system. The effect of such damping can be estimated relatively accurately. Thus, when severe wind-induced vibration problems are expected, installing auxiliary damping devices can be a reliable solution.

Various damping strategies are employed to reduce the effect of wind loads applied to tall buildings. They can be divided into two categories, passive systems and active systems. Passive systems have fixed properties, and, in order for them to perform as intended, they do not require energy, while active systems do need an "actuator" or "active control" mechanism relying on an energy source to modify the system properties against ever-changing loads. Thus, active systems are, in general, more effective than passive systems. However, due to their economy and reliability, passive systems are more commonly used than active systems in building structures. The different types of the auxiliary damping systems are summarized in Figure 12.

\section{Passive Systems}

The passive damping system can be further divided into two subcategories: (1) energy-dissipating-material-based damping systems such as viscous dampers and visco-elastic dampers, and (2) auxiliary mass systems to generate counteracting inertia forces such as tuned mass dampers (TMD) and tuned liquid dampers (TLD).

Energy-dissipating-material-based damping systems are generally installed as integral parts of primary structural systems at vantage locations, reducing the dynamic motion of tall buildings. The damping force in a viscous damper or visco-elastic damper is dependent upon the time rate of change of the deformation. Damping is accomplished through the phase shift between the force and displacement. An example of viscous dampers, installed as an integral part of the bracing members, can be found in the

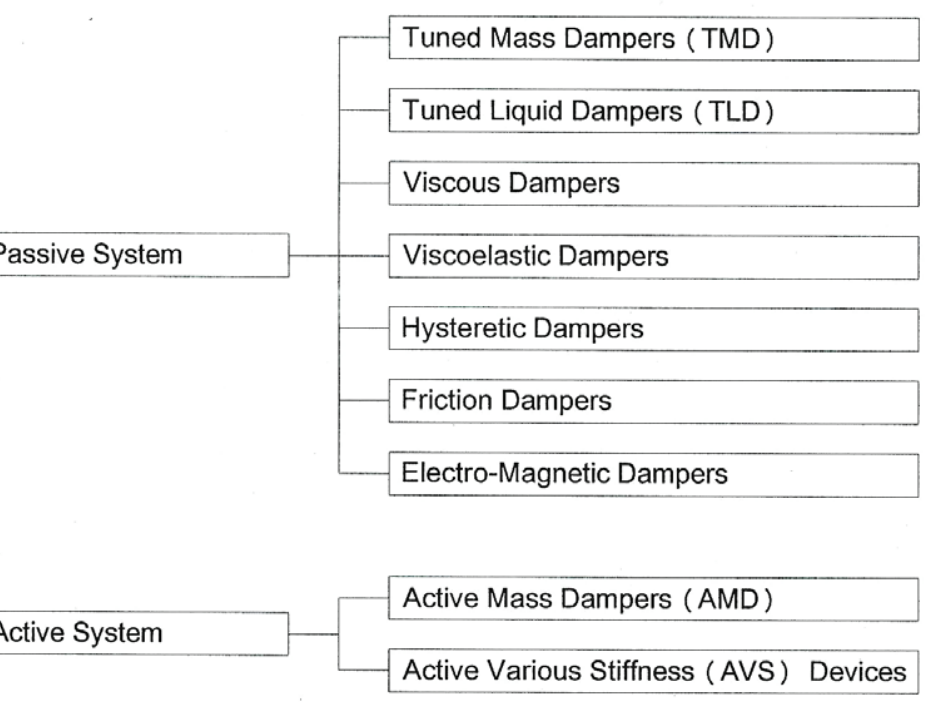

Figure 12: Auxiliary damping systems for tall buildings.

55-story Torre Mayor in Mexico City - the tallest building in Latin America at present, and visco-elastic dampers were installed in the destroyed World Trade Center Towers in New York. Other types of damping systems in which the damping mechanism is through direct dissipation of energy from the system include hysteretic damping and friction damping.

ATMD is composed of a counteracting-inertia-force-generating huge mass accompanying relatively complicated mechanical devices that allow and support the intended performance of the mass. The frequency of the TMD mass is generally tuned to the fundamental frequency of the primary structure. Thus, when the fundamental mode of the primary structure is excited, the TMD mass oscillates out of phase with the primary structure, generating counteracting inertia force. A TMD system, located near the top of the building for its best performance, is installed in a room that is usually not accessible to the public, as in the cases of the sliding type TMDs installed in the John Hancock Building in Boston and the Citicorp Building in New York. However, the pendulum-type TMD installed in the Taipei 101 tower is used as a decorative element in the building interior as well, attracting interest of visitors. 
TLD, such as tuned sloshing dampers (TSD), use waving water mass as a counteracting inertia force generator. Thus, this system can be designed using the existing water source in tall buildings, such as a pool or water tank located near the top of a building. In a TSD, sloshing frequencies are tuned by adjusting the dimensions of the water container and the depth of water. Another type of TLD is tuned liquid column dampers (TLCD), which uses a Ushaped vessel. TMD and TLD are classified further as shown in Figures 13-1 and 13-2, respectively.

\section{Active Systems}

Connor (2003) defines the active structural control system as "one that has the ability to determine the present state of the structure, decide on a set of actions that will change this state to a more desirable one, and carry out these actions in a controlled manner and in a short period time." While some passive systems, such as TMDs or TSDs, are effective only for a narrow range of loading conditions, active systems can perform effectively over a much wider range and they are a more advanced form of functional performance-driven technologies in architecture. Examples are active mass dampers (AMD) and active variable stiffness devices (AVSD).

The AMDs resemble the TMDs in appearance, although the vibration of a building is picked up by a sensor, the optimum vibration control power calculated by a computer, and the movement of the building is reduced by shifting a moveable mass with an actuator. The AVSDs continuously alter the building's stiffness to keep the frequency of the building away from that of external forces, such as earthquakes, to avoid a resonance condition. Although their cost-intensiveness and reliability issues is limiting the use of active systems at present, with more research, they have great potential for future applications.

\section{Recent Developments in the Form of Tall Buildings}

The direction of evolution of the tall building's structural systems has been toward efficiently increasing the lateral stiffness against lateral loads-primarily wind loads. In order to obtain the necessary lateral stiffness, introduced first were braced frames and MRFs followed by tubular structures, core-supported outrigger structures, and more recently diagrid structures. The interrelationship between this structural evolution and the accompanying architectural aesthetics is worth discussing. Several contemporary directions of design strategies in terms of generating new forms "outside the box," such as aerodynamic, twisted, and other forms are discussed in the following.

\section{Structural Evolution and Architectural Expression}

The inherent monumentality of skyscrapers resulting from their scale makes their architectural expression very significant in any urban context where they soar. Thus, constructing any tall building requires careful studies on aesthetic adequacy of the new structure within the existing urban context. Some structural systems for tall buildings have had major impacts on the building aesthetics, while others have had only minor impacts.

In the traditional braced frames, the braces - the main lateral stiffness provider - were generally constrained within the interior cores, and serve only for structural performance. Consequently, no aesthetic expressions had been sought from these bracings until the emergence of the exterior-braced tubular structures such as the John Hancock Center in Chicago.

In the outrigger structures, a lateral load-resisting system is extended from the conventional core to the building perimeter columns through the outriggers that connect them. This basic configuration often requires perimeter super columns and/or belt trusses at the outrigger levels, and these elements of the outrigger system are sometimes incorporated with building aesthetics. For example, the First Wisconsin Center in Milwaukee clearly expresses the belt trusses on the façade at the outrigger levels as a building aesthetic element.

Tubular structures, including superframes and recent diagrid structures, locate their major lateral load-resisting components at the building perimeters where building facades are, creating structural domination in the expression of the buildings. This performance-induced juxtaposition naturally leads to an integrative design approach between the structural system and façade system. Therefore, in tall buildings that employ these types of structural systems, technological components and architectural components of building facades are inseparable, one complementing the other. These circumstances require very intimate cooperation between architects and engineers.

The framed tube and bundled tube structures, with their dense orthogonal structural elements on the building facades, went well with the 1960s and 1970s modern architecture primarily composed of pure verticals and horizontals. On the contrary, in contemporary urban contexts, diagrid tall structures are quite dissimilar to their tall neighbors. While many contemporary aesthetic decisions are substantially guided by subjective visual judgments, the use of diagrid structures stands as an innovation that requires a partnership between technical and compositional interests. These exterior structures can create a type of aesthetics, the so-called structural expression expounded by Fazlur Khan and others (Ali, 2001; Billington, 1983). However, the notion of structural expression is now receding with the advent of other forms of aesthetic expression at present. The diagrid system remains the exception.

\section{Regional Expression}

As has been discussed earlier, the setting of most active tall building development has been shifting from North America to Asia over the last decade. The most significant trend of tall buildings constructed in various Asian countries is that they use their own regional architectural and cultural traditions as main design motives. This trend can be easily seen from notable recent tall buildings such as the Jin Mao Building in Shanghai, Petronas Towers in Kuala Lumpur (Figure 14), Landmark Tower in Yokohama, and Taipei 101 Tower in Taipei (Figure 15). Behind the traditional images are the products of the contemporary technology such as the tubular structures in the case of the Landmark Tower or the core supported outrigger structures in the cases of the Jin Mao Building and Taipei 101. Even though there is a certain level of diversity in this regional design trend, this new direction generally produces contextual architecture.

\section{Aerodynamic Forms}

In conjunction with increasing lateral stiffness against winds, a recent trend in tall building design practice is to improve aerodynamic properties of tall buildings to reduce wind forces 


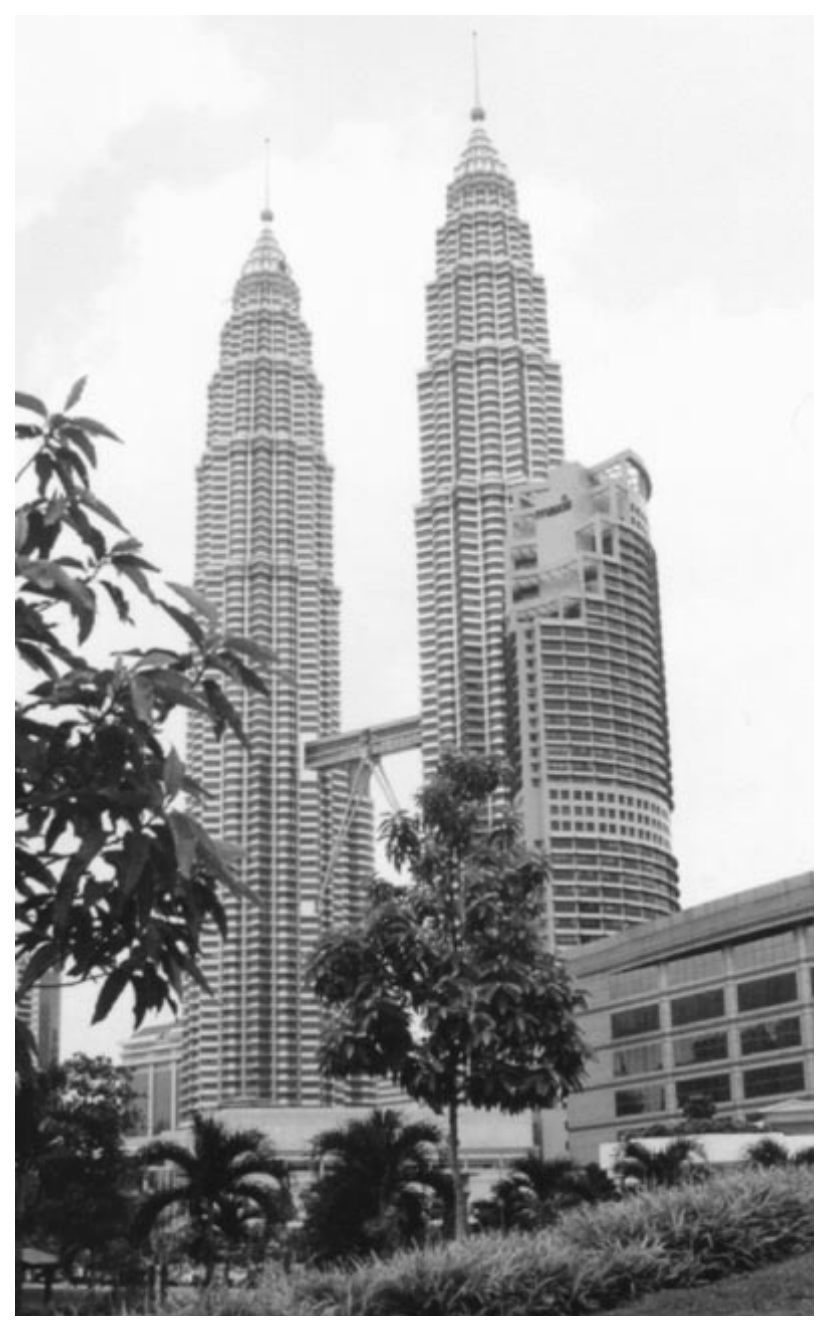

Figure 14: Petronas Tower

(Courtesy of Abbas Aminmansour).

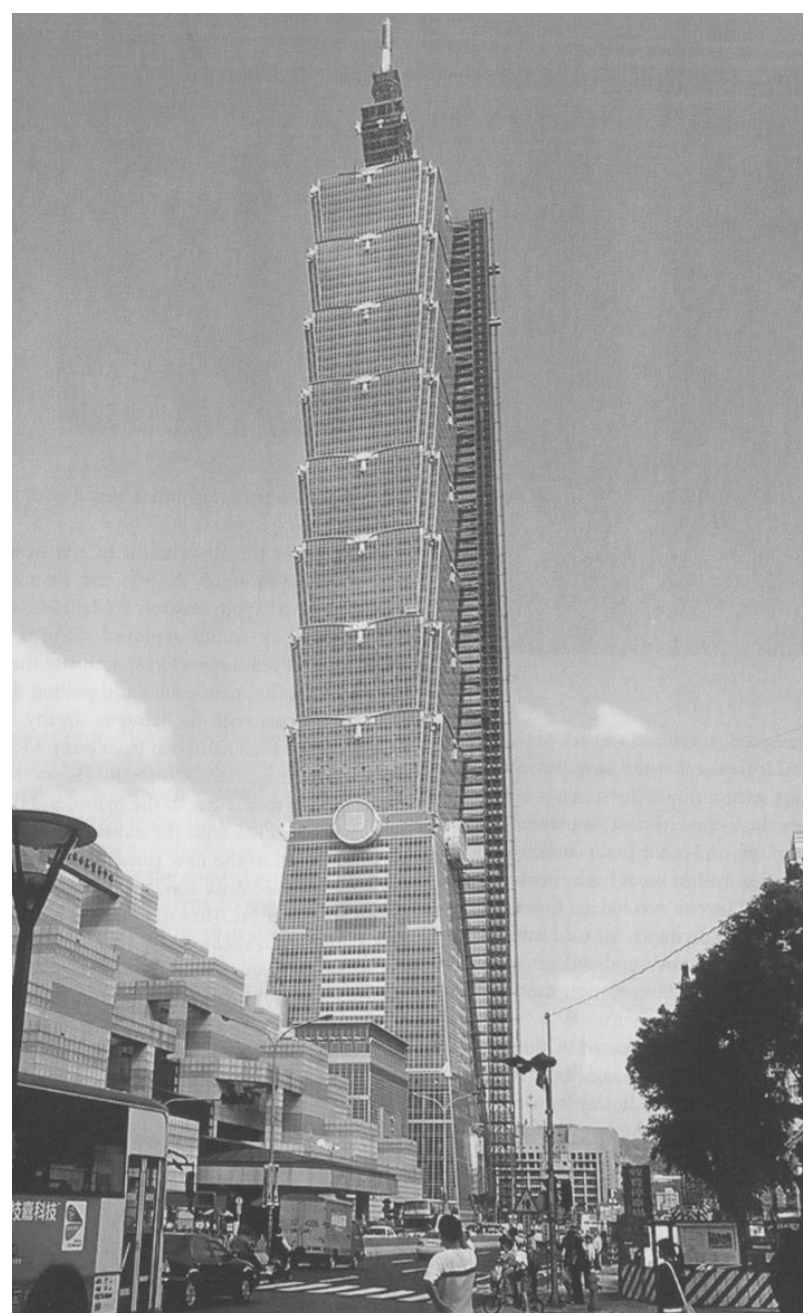

Figure 15: Taipei 101

(Courtesy of Shaw Shieh, Evergreen Consultants Ltd.)

twisting, tapering, or other building forms with discontinuities and multi-planar facades that are emerging in urban skylines.

\section{Emergence of Twisted Forms}

An interesting approach in contemporary tall building design is twisted forms. Twisted forms employed for today's tall buildings can be understood as a reaction to boxed forms of modern architecture. In fact, this contemporary architectural phenomenon is not new in architecture. It is comparable to twisted forms of Mannerism architecture at the end of Renaissance architecture. For example, in Cortile della Cavallerizza at Palazzo Ducale in Mantua, Giulio Romano designed twisted columns. This twisted form can be found again in today's tall building designs such as the Turning Torso, apartment and office tower, in Malmo, Sweden and the proposed Chicago Spire Project in Chicago designed by Santiago Calatrava.

In general, twisted forms are effective in reducing vortex-sheddinginduced dynamic response of tall buildings by disturbing vortex shedding. In terms of static response, twisted forms are not beneficial. If solid sections are considered, the moment of inertia of a square plan is the same regardless of its twisted angle (Figure 16). Thus, the displacements due to bending are the same as well. However, if the building type frames are considered, the lateral stiffness of the twisted forms is not as large as that of straight forms. responses. In addition to today's pluralistic architectural styles promoting diversity, this logic of rational aerodynamics has led to 


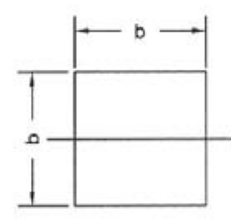

$\mathrm{l} x=\frac{\mathrm{b}^{4}}{12}$

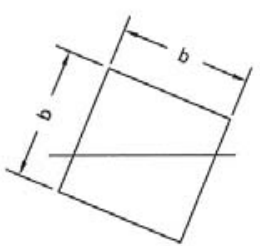

$I_{x}=\frac{b^{4}}{12}$

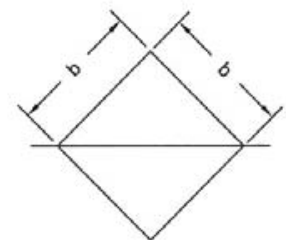

$\mathrm{Ix}_{\mathrm{x}}=\frac{\mathrm{b}^{4}}{12}$

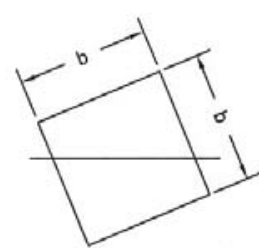

$\mathrm{I}_{\mathrm{x}}=\frac{\mathrm{b}^{4}}{12}$

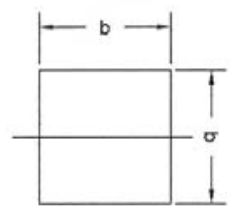

$\mathrm{Ix}_{\mathrm{x}}=\frac{\mathrm{b}^{4}}{12}$

Figure 16: Moment of inertia of twisted forms.

\section{Free Forms}

The number of free-form tall building projects has been rapidly increasing these days. In the past, only a few free-form tall building projects were proposed by some architects like Peter Eisenman and Frank Gehry, but they were never built. Within the context of tubular design, however, free-form structure is exemplified by the Sears Tower and One Magnificent Mile Building, both in Chicago, which employed a bundled tube system (Ali, 1990). Today, many free-form tall buildings are designed and actually constructed. It

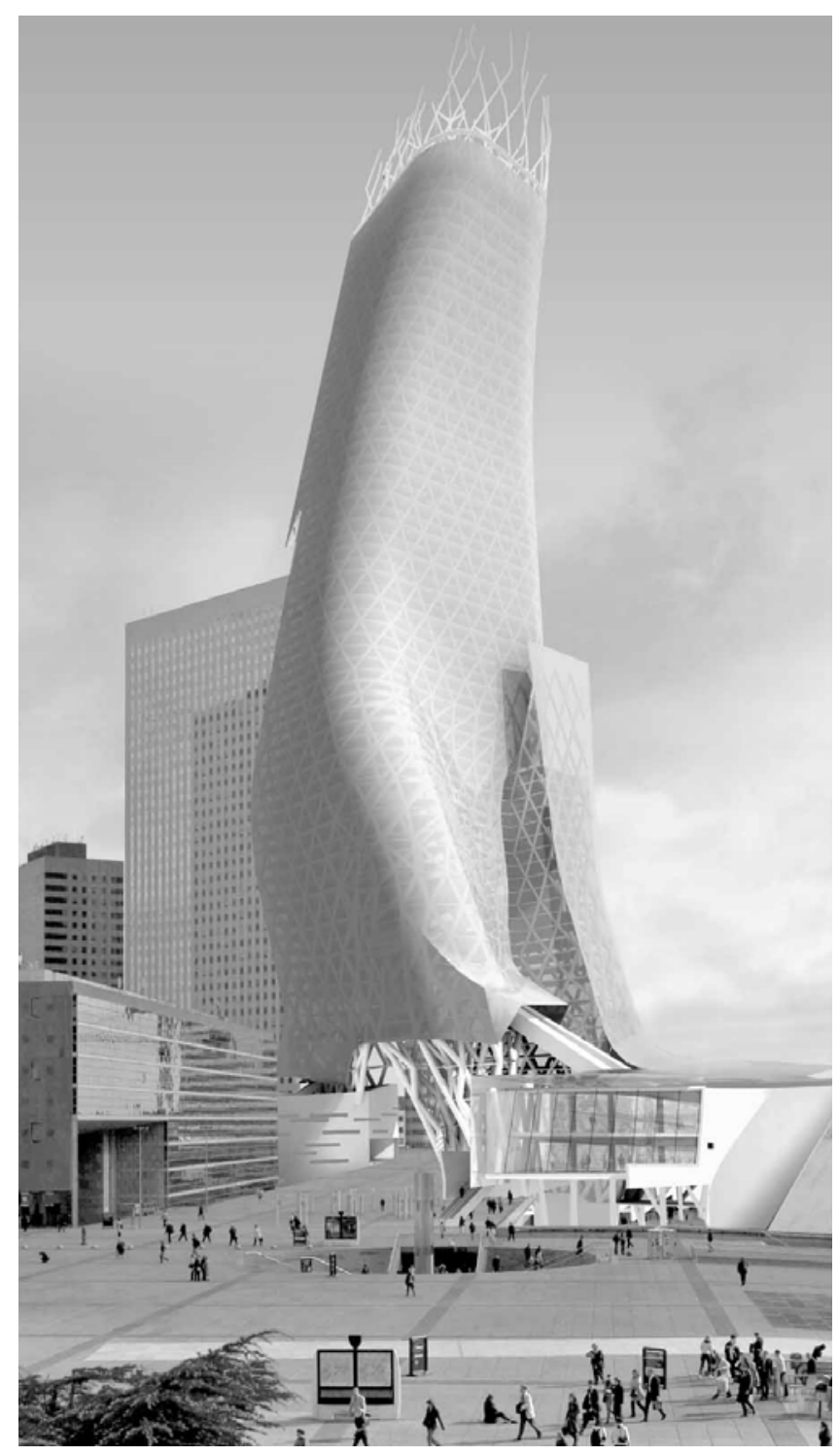

Figure 17: Phare Tower (Courtesy of Unibail-Morphosis). was quite a difficult task to perform the structural designs and analyses of irregular free-form tall buildings in the past. It can now be done relatively easily with the development of sophisticated structural design and analysis using computer software. Relying on the powerful support of contemporary structural engineers, some architects find their design solutions in free forms feasible. These architects include Daniel Libeskind, Zaha Hadid and Thom Mayne of Morphosis. Even though the supporting structural systems behind the free forms vary depending on the project-specific situations, diagrids are often employed as primary structures for free-form tall buildings as can be observed from Daniel Libeskind's Fiera Milano Tower and Morphosis' Phare Tower in La Defense (Figure 17). Other contemporary free-form (poetic, cinematic and tilted) tall buildings include Hadid's Dancing Tower in Dubai and Peter Pran's Oil Company Headquarters in Jeddah (Figure 18, unbuilt) and The Sail @ Marina Bay in Singapore (Figure 19).

\section{Future Prospects}

Development of new technology occurs based upon necessity, and the technology evolves towards enhanced efficiency. The development of braced frame structures to produce more rentable spaces in dense urban lands by constructing tall buildings in the past and their evolutionary paths up to the present towards even taller and more efficient structures to maximize land uses more economically are within this track. Tall buildings, which began from with 10-story office towers in the late nineteenth century, have evolved to megastructures like the Burj Dubai, which is over 150 stories and will be the tallest building in the world at the time of its completion in 2009.

There continues to be a need for building upward. Populations worldwide have grown rapidly, and migration of populations from rural areas to urban, has resulted in high-density mega cities. Denser cities with megastructures are more efficient in terms of energy consumption and land use. By making a city smaller and denser, the power grid becomes smaller, making the transfer of electrical energy more efficient. The need for automobile transportation declines as well as the need for personal transportation, which is a large contributor to the problems of efficient energy consumption and pollution. By creating denser cities with tall buildings, more natural green areas can be saved globally. However, compactness will result in crowding and hence a balance must be struck.

The idea of a megastructure, which can be viewed as an extremely large multi-use tall building containing almost a city within it, is not new. In 1956, Frank Lloyd Wright proposed the Mile-High Illinois Tower in Chicago. It was composed of five vertical zones of 100 stories each. More recently proposed megastructure projects 


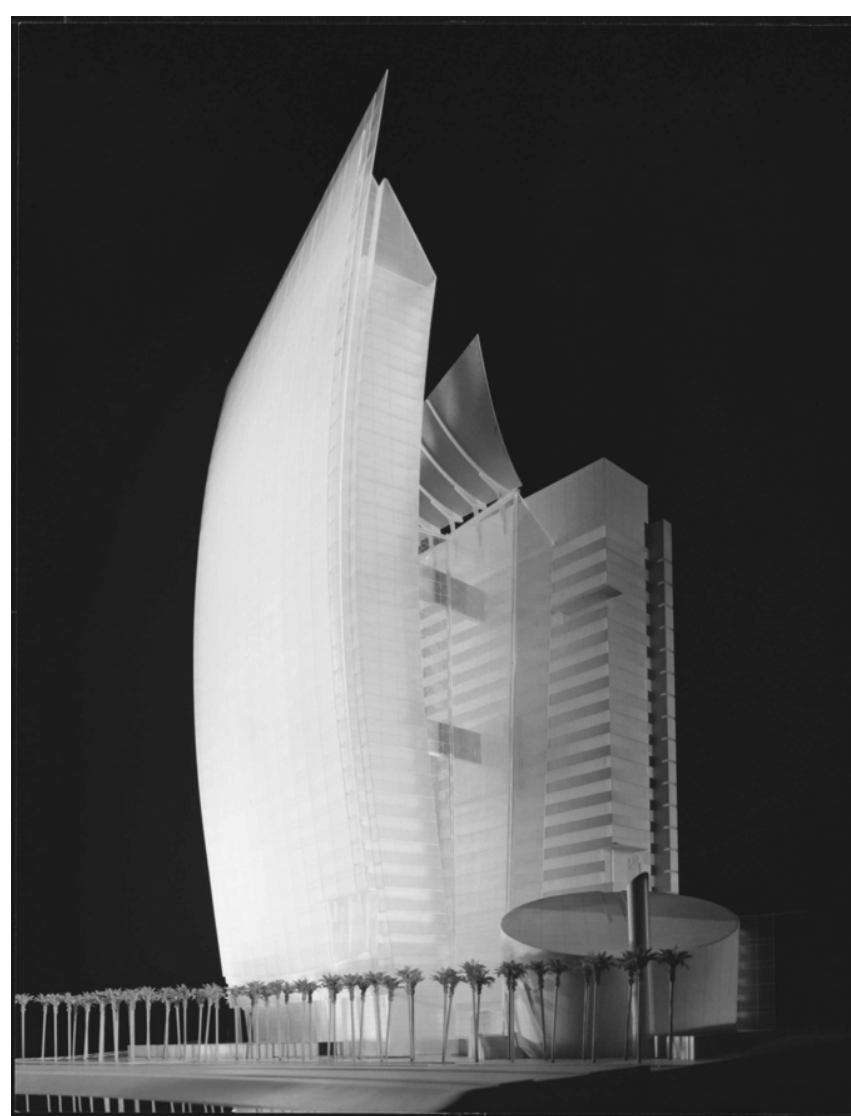

Figure 18: Oil Company Headquarters, unbuilt (Courtesy of Peter Pran/Ellerbe Becket; Photo by Dan Cornish).

include the Bionic Tower in Shanghai designed by Celaya, Pioz \& Cevera Architects, Sky City 1000 in Tokyo (Figure 20) and Holonic Tower developed by Takenaka Corporation, X-Seed 4000 in Tokyo designed by Taisei Construction Corporation, and Millennium Tower in Tokyo designed by Norman Foster (Figure 21).

The range of the heights of these recently proposed megastructures are from about $600 \mathrm{~m}$ tall Holonic tower to $4000 \mathrm{~m}$ tall X-Seed 4000. A building height of $500 \mathrm{~m}$ is already reached by Taipei 101 , and $700 \mathrm{~m}$ will probably be reached soon by Burj Dubai. For the future megastructures in megacities, it is expected that the building height will be continuously increased in conjunction with the improvements in technology in structural systems, materials, elevators, fire protection, energy efficiency, and damping systems. Better strategies of integration are required to accomplish highperformance skyscrapers in the future (Ali \& Armstrong, 2007). The future primary structural system may be speculated as an unprecedented newly developed system, or a variation of an existing system, or possibly a logical vertical combination of two or more existing systems to build higher.

With regard to the auxiliary damping system, the primary direction of its evolution has been toward the enhanced performance of motion control. In addition to this trend, future damping devices will be used not only for dissipating energy but also for generating energy-harnessing building motions. Considering the increased interest in sustainable architecture that includes energy-efficient design, it is expected that the research on this design direction will become very important in both academia and practice.

Another prospected direction, especially with regard to the design of mass-type damping devices, is developing space-saving strategies through the system integration between the damper mass and other existing building systems. For the best performance, mass type dampers are installed close to the top of the building, occupying, in a sense, the most valuable near-top building space. By system integration, this space can be saved for other functions. Damping systems are traditionally treated by designers as an expensive supplemental item added to a building to reduce motions for occupant comfort. For more tall buildings changing the city's skylines, this notion should be changed. Rather than considering it as an afterthought, if necessary, damping systems should be thought of as a basic ingredient of structural design of tall buildings and implemented in innovative ways in which they occupy little space and are more effective.

Finally, it is expected that architects and engineers will be exploring the aesthetic potentials not only of the primary structural systems but also of the auxiliary damping systems.

\section{Conclusions}

This paper has presented a general review of structural systems for tall buildings. Unlike the height-based classifications in the past, a system-based broad classification (i.e., exterior versus interior structures) has been proposed. Various structural systems within each category of the new classification have been described with emphasis on innovations. Evolution of structural systems in conjunction with architectural forms and aesthetics, from the conventional rigid frame to the more recent re-formed "out-of-

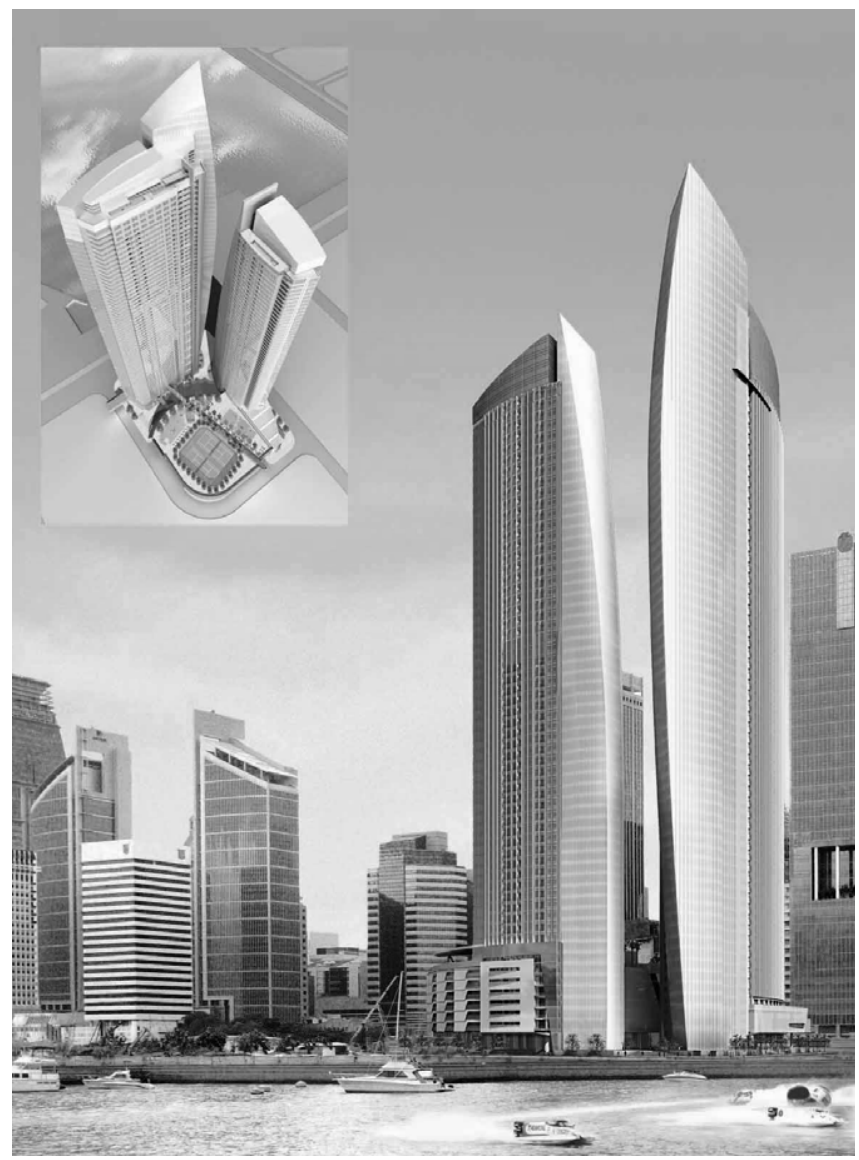

Figure 19: The Sail @ Marina Bay

(Courtesy of Peter Pran, NBBJ and Publicis Singapore). 


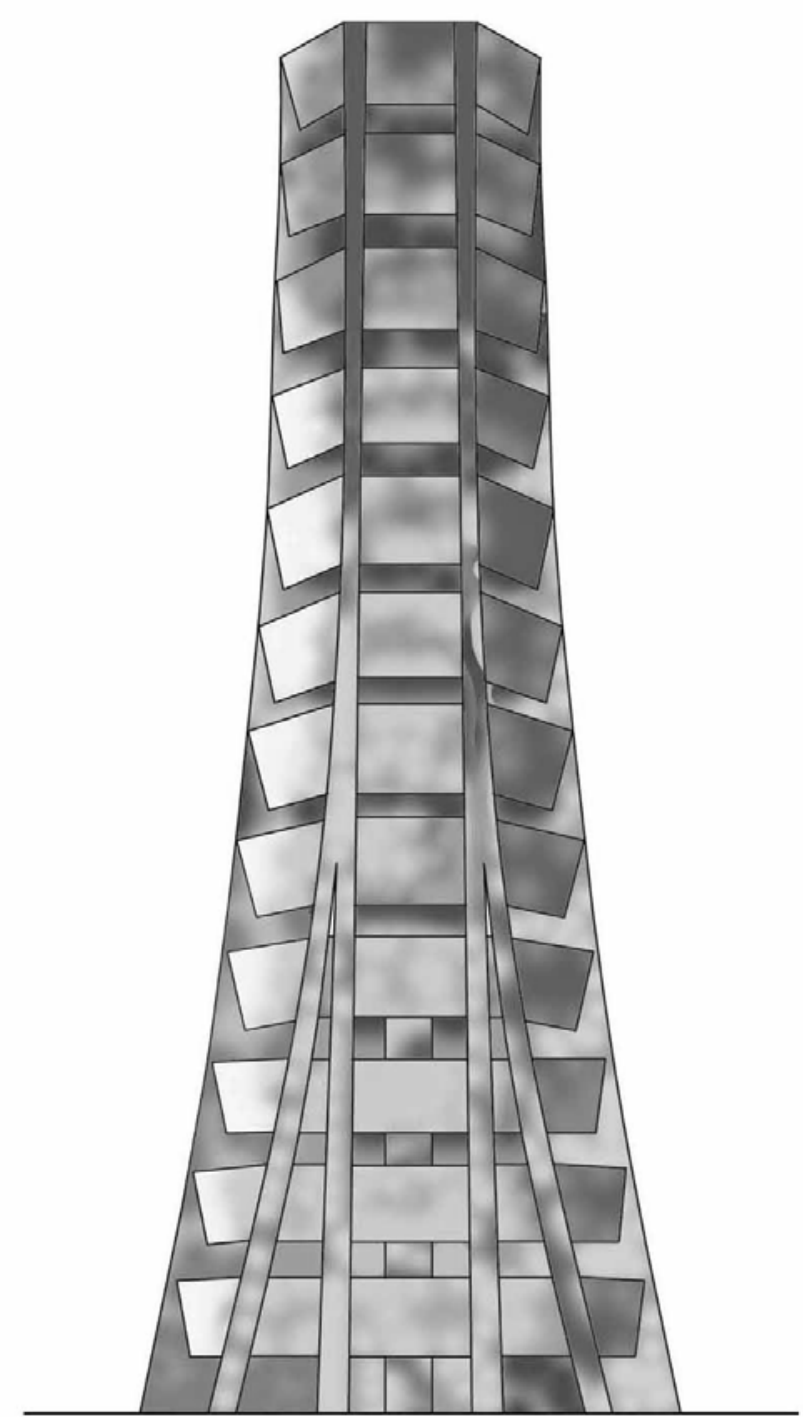

Figure 20: Sky City 1000.

the-box" systems, has been traced. Speculations on the future possibilities of tall buildings from a structural viewpoint have been made. It is concluded that the tall building phenomenon will continue in a greater scale to meet the needs of the growing population in future large cities.

This paper demonstrates that structural systems have come a long way since the late nineteenth century when they were conceived as framed systems. There is a need for creating a comprehensive database of structural systems for tall buildings throughout the globe. The innovative and emerging systems can be placed within the classification scheme presented in this paper and can be continuously updated for the benefit of the practicing professionals and researchers.

With the development of increasingly taller buildings using lighter members, serviceability issues like lateral sway, floor vibration, and occupant comfort need to be given more attention by researchers. The damping systems discussed in this paper can be very helpful in this regard. Future innovations in passive and cost-effective active damping systems and associated technologies are highly desirable.

More research is needed for exterior structural systems which are technically more efficient as was seen in Table 2-2 and Figure 4-2. However, placing structural frames on the perimeter has some drawbacks from an architectural point of view. Structural solutions to overcome these problems are very much needed. Efficient structural systems in seismic zones also need to be further investigated.

Innovative structural systems for the next generation of sustainable, ultra-high tall buildings and megastructures should be developed. A major challenge for multi-use tall structures is to make them adaptive to possible changes in occupancy at different floor levels responding to the demands of the prevailing real estate market.

Finally, the newly evolving "out-of-the-box" systems should be seriously investigated in terms of their structural efficiency and economy. Cost analysis of such irregular systems can be performed to determine the relative economic efficiency of these systems considering various geometric parameters. Such studies will suggest if the complexities involved in these buildings justify their continued construction within the constraint of limited resources. 


\section{Acknowledgement}

The authors wish to thank Professor Gary Moore, editor of the Architectural Science Review, for inviting this paper.

\section{References}

Abalos, I., \& Herreros, J. (2003). Tower and Office: From Modernist Theory to Contemporary Practice. Cambridge, MA: MIT Press.

Ali, M.M. (1990). Integration of structural form and esthetics in tall building design: the future challenge. In L.S. Beedle \& D. Rice (Eds.), Proceedings of the $4^{\text {th }}$ World Congress of the Council on Tall Buildings and Urban Habitat: Tall Buildings-2000 and Beyond. Chicago, IL: Council on Tall Buildings and Urban Habitat, 3-12.

Ali, M.M. (2001). Art of the Skyscraper: The Genius of Fazlur Khan. New York: Rizzoli.

Ali, M.M. (2005). The skyscraper: epitome of human aspirations. In Proceedings of the $7^{\text {th }}$ World Congress of the Council on Tall Buildings and Urban Habitat: Renewing the Urban Landscape [CD-ROM]. Chicago, IL: Council on Tall Buildings and Urban Habitat.

Ali, M.M., \& Armstrong, P.J. (Eds). (1995). Architecture of Tall Buildings. Council on Tall Buildings and Urban Habitat Monograph. New York: McGraw-Hill.

Ali, M.M., \& Armstrong, P.J. (2007). Strategies for integrating sustainable tall buildings. In Proceedings of the AIA Convention 2007: Growing Beyond Green. Washington, DC: American Institute of Architects.

Billington, D.P. (1983). The Tower and the Bridge: The New Art of Structural Engineering. Princeton, NJ: Princeton University Press.

Corrin, M.E., \& Swensson, K.D. (1992). Eccentrically braced frames: Not just for seismic design. Modern Steel Construction, 33-37.

Connor, J.J. (2003). Introduction to Structural Motion Control. New York: Prentice Hall.

Huxtable, A.L. (1984). The Tall Buildings Artistically Reconsidered: The Search for a Skyscraper Style. New York: Pantheon Books.
Iyengar, H. (1986). Structural and steel systems. Techniques and Aesthetics in the Design of Tall Buildings, Bethlehem, PA: Institute for the Study of High-Rise and Habitat, Lehigh University, 57-69.

Khan, F.R. (1967). The John Hancock Center. Civil Engineering, $37(10), 38-42$.

Khan, F.R. (1969). Recent structural systems in steel for high-rise buildings. In Proceedings of the British Constructional Steelwork Association Conference on Steel in Architecture. London: British Constructional Steelwork Association.

Khan, F.R. (1972). Influence of design criteria on selection of structural systems for tall buildings, In Proceedings of the Canadian Structural Engineering Conference. Toronto: Canadian Steel Industries Construction Council, 1-15.

Khan, F.R. (1973). Evolution of structural systems for high-rise buildings in steel and concrete. In J. Kozak (Ed.), Tall Buildings in the Middle and East Europe: Proceedings of the 10 $0^{\text {th }}$ Regional Conference on Tall Buildings-Planning, Design and Construction. Bratislava: Czechoslovak Scientific and Technical Association.

Khan, F.R., \& Sbarounis, J. (1964). Interaction of shear walls and frames in concrete structures under lateral loads. Structural Journal of the American Society of Civil Engineers, 90(ST3), 285-335.

Kowalczyk, R., Sinn, R., \& Kilmister, M.B. (Eds) (1995). Structural Systems for Tall Buildings (Council on Tall Buildings and Urban Habitat Monograph). New York: McGraw-Hill.

Moon, K. (2005). Dynamic Interrelationship between Technology and Architecture in Tall Buildings. Unpublished PhD Dissertation, Massachusetts Institute of Technology.

Popov, E.P. (1982). Seismic framing systems for tall buildings. Engineering Journal/American Institute of Steel Construction, 19(Third Quarter), 141-149.

Schueller, W. (1986). High-Rise Building Structure (2nd ed). Malabar, Florida: Krieger.

Taranath, B. (1998). Steel, Concrete, \& Composite Design of Tall Buildings. New York: McGraw-Hill. 